\title{
The effects of CFRP orientation on the strengthening of reinforced concrete structures
}

\author{
Mehdi M. Lima ${ }^{1}$, Jeung-Hwan Doh ${ }^{1 *}$, Muhammad N. S. Hadi ${ }^{2}$ and Dane Miller ${ }^{1}$ \\ ${ }^{1}$ School of Engineering, Griffith University, Gold Coast, QLD, Australia \\ ${ }^{2}$ School of Civil, Mining and Environmental Engineering, University of Wollongong, Wollongong, NSW, Australia
}

\begin{abstract}
SUMMARY
In recent years, the strengthening and retrofitting of structural members using externally bonded carbon fibre reinforced polymer (CFRP) materials has gained a great deal of attention. This has eventuated from the superior properties of composite materials, including high elastic modulus, higher strengths and lighter weights. This paper presents a finite element analysis that has been validated against laboratory tests of two reinforced concrete (RC) beams, two columns, two slabs and six walls. The main focus is on the ultimate failure load of these members as they have different CFRP orientations to the loading direction. The analysis result shows a sound agreement with the experimental data regarding the ultimate failure load of $\mathrm{RC}$ samples, except for the RC wall. In fact, the RC wall, while under eccentric axial load, confirmed that the CFRP orientation was parallel to the loading direction, and it proved to be an insignificant contribution in the ultimate failure load of the samples. This finding demonstrates that more experiments should be considered when investigating the influence of CFRP on the ultimate strength of strengthened RC walls. Copyright @ 2016 John Wiley \& Sons, Ltd.
\end{abstract}

Received 21 September 2015; Revised 17 January 2016; Accepted 16 February 2016

KEY WORDS: concrete structures; confined concrete; carbon fibre reinforced polymer; reinforced concrete wall; strengthening; concrete damage plasticity

\section{INTRODUCTION}

A large number of concrete structures need to be strengthened due to the deterioration of structures that is largely influenced by environmental effects, poor initial construction or a lack of required maintenance. Based on the load-carrying capacity of structures and demand, a vast array of strengthening methods may be utilized. While the traditional method of the strengthening/retrofitting of concrete structures is commonly used steel plates and jackets, there are some disadvantages, including an increase in the self-weight of structures, and that it is labour-intensive and susceptible to fatigue and corrosion. Due to the rapid advancement in construction material, technology has led to the inspiring achievement of being able to secure safer, more economical and functional buildings (Bakis et al., 2002). Of the innovative materials, fibre reinforced polymer (FRP) appears to be a superb solution for the retrofitting and strengthening of reinforced concrete (RC) structures because of its unique properties, including high strength-to-weight ratio, high fatigue endurance, environmental degradation and corrosion resistance (Hollaway and Head, 2001; Teng et al., 2002; Tumialan et al., 2002; Teng et al., 2003; Zhang, Hsu C-T, and Moren, 2004; Zhang and Hsu, 2005; Zhao and Zhang, 2007). In contrast to the traditional method of retrofitting structures, the handling and transportation of FRP is much more user-friendly. It is also durable and very flexible when applying it to the various shapes of structural members. Further, it is easy to install, with a negligible increase in structural size and weight (Alsayed, Al-Salloum, and Almusallam, 2000; Clarke, 2003; Obaidat, Heyden, and Dahlblom, 2010; Meneghetti et al., 2014).

*Correspondence to: Jeung-Hwan Doh, School of Engineering, Griffith University, Gold Coast, QLD 4222, Australia. E-mail: J.doh@griffith.edu.au 
The application of FRP is dependent upon the type of structural member plus its behaviour. It can be used to enhance the load (axial, flexural or shear) capacities, ductility, rigidity, the remaining fatigue life and the durability against harsh environments. An extensive experimental research has already been conducted on FRP application on the strengthening of concrete structures (Spadea, Bencardino, and Swamy, 1998; Pantelides et al., 1999; Neale, 2000; Rahimi and Hutchinson, 2001; Nanni, 2003; Thanoon et al., 2005; Kim et al., 2012; Napoli et al., 2013) and also national codes of standards devoted separate chapter for the FRP applications (JSCE, 2000; FIB14, 2001; ISIS, 2001; ACI 440, 2002; TR 55, 2012).

However, the effectiveness of confinement between FRP and concrete is reportedly much reduced by applying load at eccentricity, particularly lateral FRP confined structural elements such as columns and walls. In addition, to the best of author's knowledge, there has not been finite element method (FEM) investigation on the behaviour of RC walls under eccentric axial loads. Therefore, this paper focuses on a comparative study of using finite element analysis. The experimental and analytical work of beams, columns, slabs and walls has contributed to a greater understanding of the behaviour of FRP confinement with various concrete elements that have been utilized in this study.

This paper initially presents a brief overview of an experimental programme undertaken by previous researchers on strengthened RC beams, columns, slabs and walls. The load capacity of the typical test results is then compared with predicted results from the ABAQUS package. A nonlinear geometry and material properties were employed to analyse the behaviour of RC elements.

\section{APPLICATION OF CFRP IN CONCRETE ELEMENTS}

Many researchers have investigated the flexural and shear behaviour of strengthened/retrofitted RC beams, with some review papers also being published (Bakis et al., 2002; Smith and Teng, 2002; Pendhari, Kant, and Desai, 2008; Chin, Shafiq, and Nuruddin, 2014). Usually, the FRP sheet/laminate is used in the tension side of the beam and perpendicular to cracks; the strength and stiffness increases significantly as compared with situations where fibres are placed oblique to the cracks (Norris, Saadatmanesh, and Ehsani, 1997; Grace et al., 1999; Hong et al., 2010; Altin et al., 2011; Rahai and Saberi, 2011; Kim, Kim, and Kim, 2015; Lu et al., 2015; Tanarslan, Kumanlioglu, and Sakar, 2015; zgür Yurdakul and Avşar, 2015). The effect of FRP on the ultimate capacity of $\mathrm{RC}$ beams has been reported in several research outcomes. Some of these results, including strengthening scheme and the enhancement of the ultimate strength, are presented in Table. 1.

The FRP confinement has been used for the strengthening of both normal and high-strength concrete columns. To investigate the behaviour of FRP-confined concrete columns, experimental tests and theoretical methods have been applied (Barghi, Azadbakht, and Hadad, 2012). The effect of FRP in the ultimate capacity of RC columns is reported in the previous studies. Some of these results, including strengthening scheme, load type and enhancement of the ultimate strength, are presented in Table. 2. The effect of FRP in the ultimate capacity of RC slabs has been investigated. Some of these results, including strengthening scheme and enhancement of the ultimate strength, are presented in Table. 3. Based on these results, the CFRP significantly enhanced the ultimate strength of slab by up to $184 \%$ in some cases.

Wall panels often experience eccentric loads due to a range of loading conditions including corbel element applied to the wall, imperfections in construction, an uneven loading condition on top of the wall or due to temporary loading during operation and/or maintenance. Many researchers have investigated the behaviour of RC walls with various material properties, geometry and boundary conditions (Saheb and Desayi, 1989, 1990; Doh and Fragomeni, 2005; Doh and Fragomeni, 2006; Fragomeni, Doh, and Lee, 2012). However, little research has been carried out on the CFRP strengthening method on the RC wall under eccentric axial loads. Mohammed, Ean and Malek (2013) conducted experiments on 16 one-way RC walls with two different CFRP layouts on the wall surface. Authors observed that the CFRP applications on RC walls could increase the ultimate strength of the wall from $10 \%$ up to $80 \%$, depending on the opening size and CFRP arrangement. 
THE EFFECTS OF CFRP ORIENTATION ON RC STRUCTURES

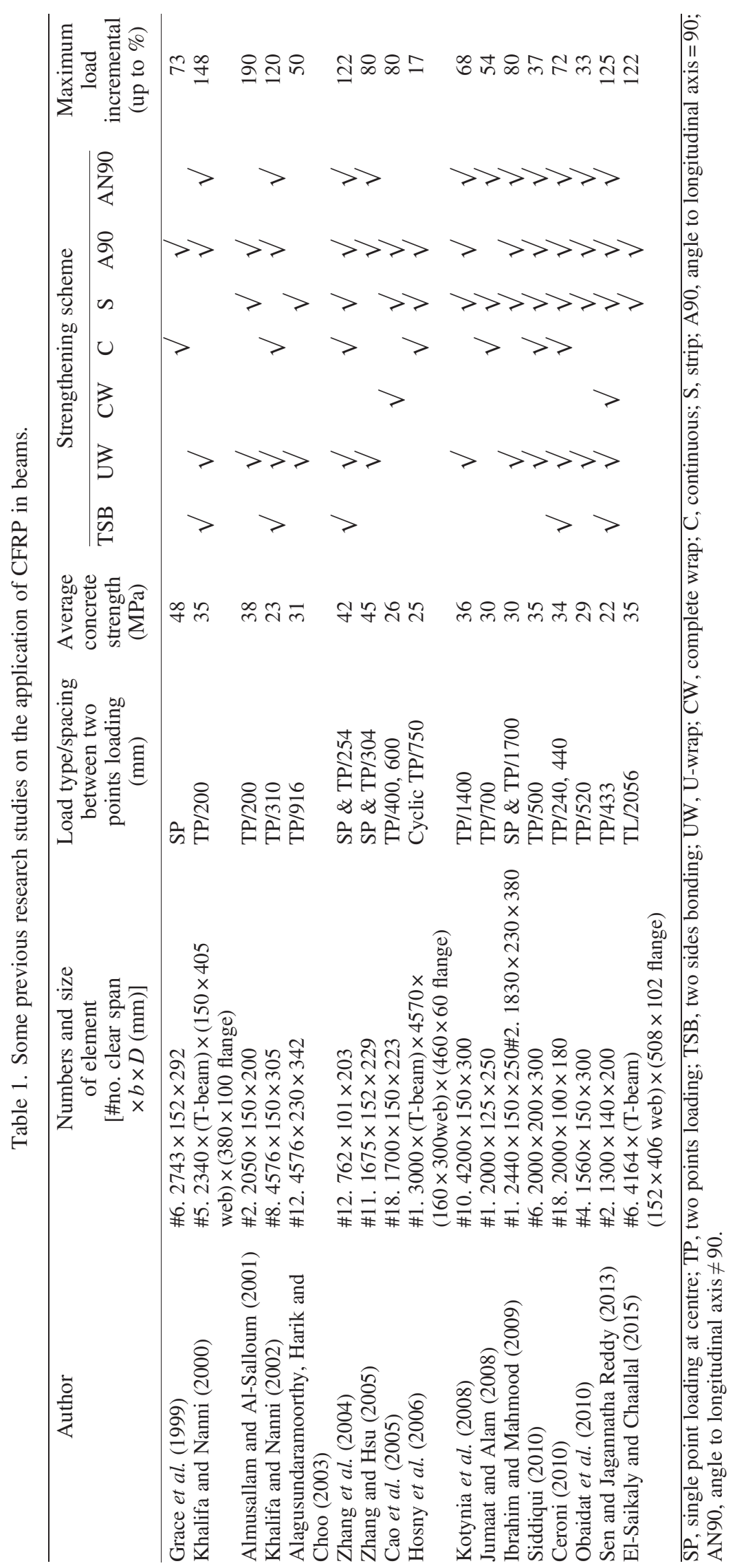


M. M. LIMA $E T A L$.

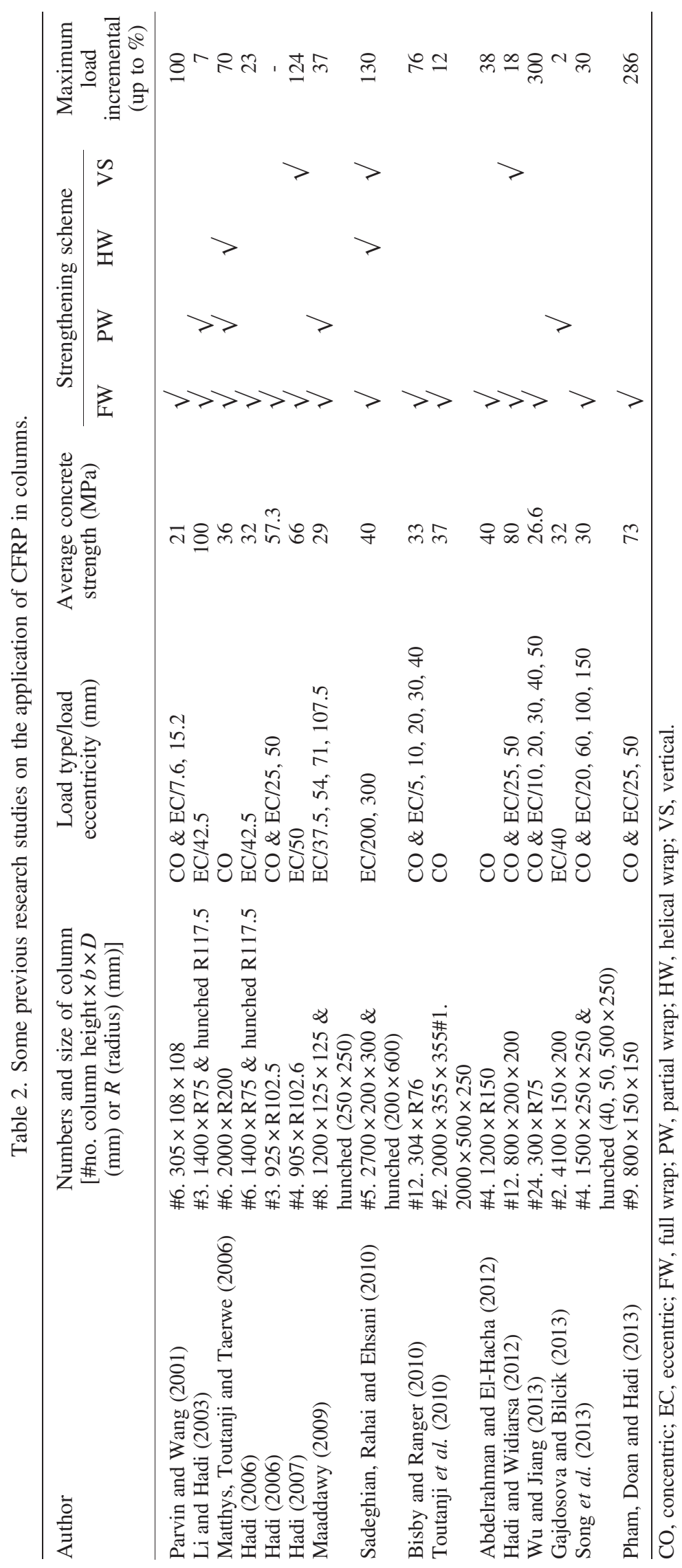


THE EFFECTS OF CFRP ORIENTATION ON RC STRUCTURES

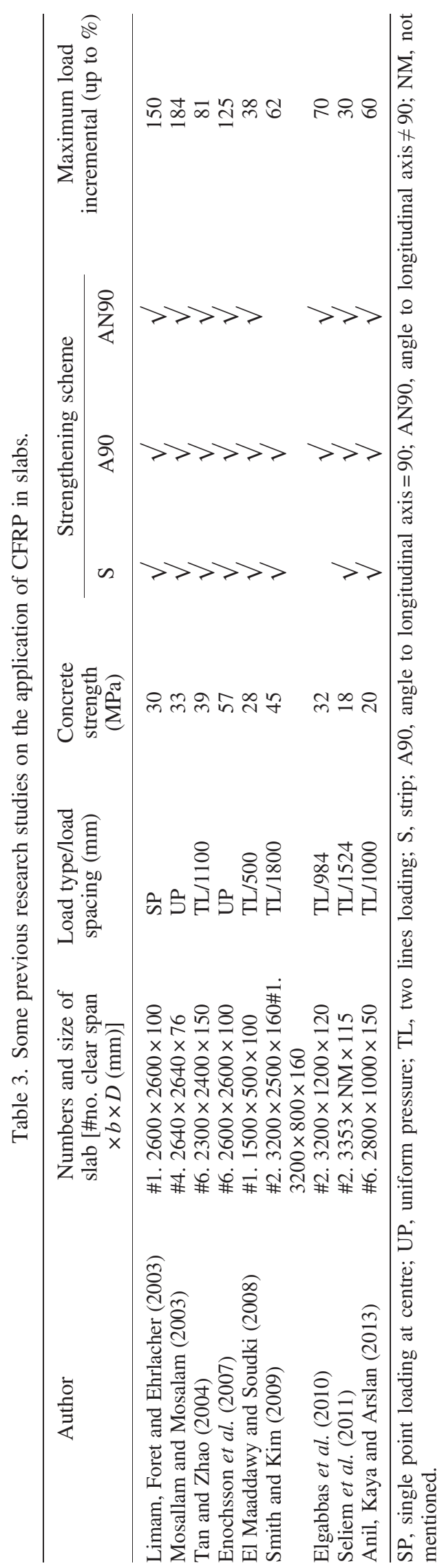


The CFRP sheet orientation in a strengthened beam, column and slab is perpendicular to the loading direction (Figures 1 and 2(a)). In these situations, fibres in CFRP will contribute to the carrying of the load by stretching through its principal direction. Therefore, the usage of CFRP in these elements enhances the ultimate strength of the member. It should be noted that, in the RC wall panels, the loading direction and CFRP's fibre orientation are parallel. As RC walls experience a shortening in the fibre's direction, a lower contribution of CFRP in ultimate failure load is expected (Figure 2(b)). As little research has been conducted on strengthening of RC walls, it is necessary to evaluate the behaviour of the wall through the numerical FEM as it is a cost-effective and time-effective method.

Using the current experimental test samples (Smith and Kim, 2009; Siddiqui, 2010; Hadi and Widiarsa, 2012; Mohammed et al., 2013), comparison tests were carried out for the performance of the FEM. This validation study is utilized to model the behaviour of beam, column, slab and RC walls strengthened by CFRP.

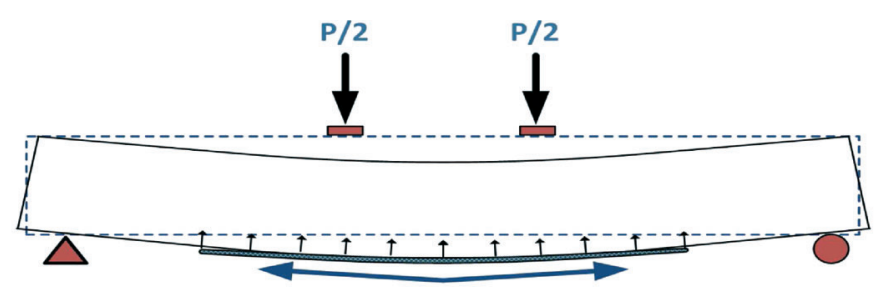

(a) Beam

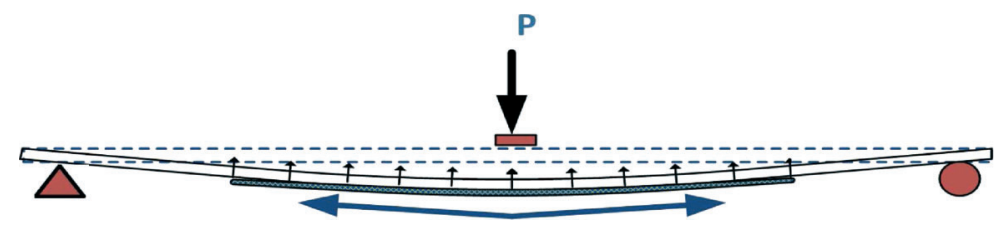

(b) Slab

Figure 1. Loading direction and CFRP orientation.

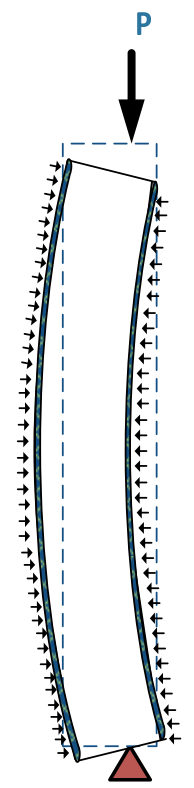

(a) Column

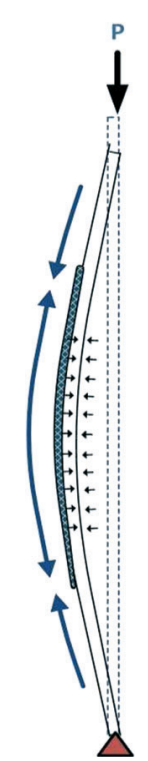

(b) RC wall

Figure 2. Loading direction and CFRP orientation. 


\section{EXPERIMENTAL WORK}

Experimental data were obtained from previous experiments on strengthened beams (Siddiqui, 2010), columns (Hadi and Widiarsa, 2012), slabs (Smith and Kim, 2009) and RC walls (Mohammed et al., 2013). The detailed information of these experiments and results can be found in the original papers. The following section is a brief description of each experiment, as well as the material properties and the enhancement of ultimate strength. The FRP material properties are presented in Section 4.5. In this study, all experiments have been designated with $\mathrm{N}$ and $\mathrm{S}$ at the beginning for non-strengthened and strengthened specimens, respectively. Therefore, the nomenclature of beams, NB and SB, are referring to the non-strengthened and strengthened beams. The same procedure is used for slabs (NS and SS), columns (NC and SC), walls (NW and SW) for non-strengthened and strengthened samples. Also, in RC walls, two different CFRP layouts are considered as SW-A and SW-D for alongside and diagonal applications, respectively. The wall number is also shown with a number.

\subsection{Beam}

Six RC beams with two different reinforcement arrangements and three FRP patterns were loaded with a four-point bending configuration with a clear span (distance between supports) of $2000 \mathrm{~mm}$, with a distance between loads of $500 \mathrm{~mm}$. From these experiments, two beams (with and without CFRP) were chosen for numerical simulation. The beams were $300 \mathrm{~mm}$ high, $200 \mathrm{~mm}$ wide and $2000 \mathrm{~mm}$ long. The longitudinal steel reinforcement consisted of three $\varphi 14$ for tension and one $\varphi 6$ for compression. Shear reinforcement was sufficiently provided with $\varphi 10$ at $100 \mathrm{~mm}$ rebars (as seen in Figure 3). The control beams were loaded up to failure, and in the other case, the CFRP was applied as the flexural strengthening scheme, as well as two u-shaped anchors at the end of the beam near the restraint. The concrete compressive strength was $35 \mathrm{MPa}$ for both cases, and yield stress of reinforcement was $420 \mathrm{MPa}$.

Application of CFRP increased the ultimate failure load from $197.2 \mathrm{kN}$ to $255.2 \mathrm{kN}$ for NB and SB samples, respectively. This is about $29.5 \%$ gain in the ultimate strength of the beam (Siddiqui, 2010).

\subsection{Column}

Sixteen identical RC columns were tested, with 12 of them under compression loading and four under flexural loading. Three different FRP confinements were investigated. From these experiments, two columns (with and without CFRP) under eccentric compression loading (eccentricity $=25 \mathrm{~mm}$ ) were chosen for numerical simulation. The columns had a square cross-section with a side dimension of $200 \mathrm{~mm}$ and a height of $800 \mathrm{~mm}$. The concrete cover was $20 \mathrm{~mm}$ on each side of the specimen, as well as on the top and bottom. All corners of the square cross-section were rounded (radius of $34 \mathrm{~mm}$ ) in order to prevent the premature failure and to provide sufficient effect of confinement of the columns. The longitudinal reinforcement consisted of four $\varphi 12$, and the transverse reinforcement was $\varphi 8$ spaced at $100 \mathrm{~mm}$, while the distance was $50 \mathrm{~mm}$ at both ends as seen in Figure 4(a). The control column was loaded up to failure, and in the strengthened case, the CFRP was applied as one layer of CFRP with horizontal orientation (Figure 4(b)). A special loading plate and mechanism were designed and used in this study (Figure 4(c)). The concrete compressive strength was $79.5 \mathrm{MPa}$ for both cases, and yield stress of longitudinal reinforcement and stirrups were $564 \mathrm{MPa}$ and $516 \mathrm{MPa}$, respectively.

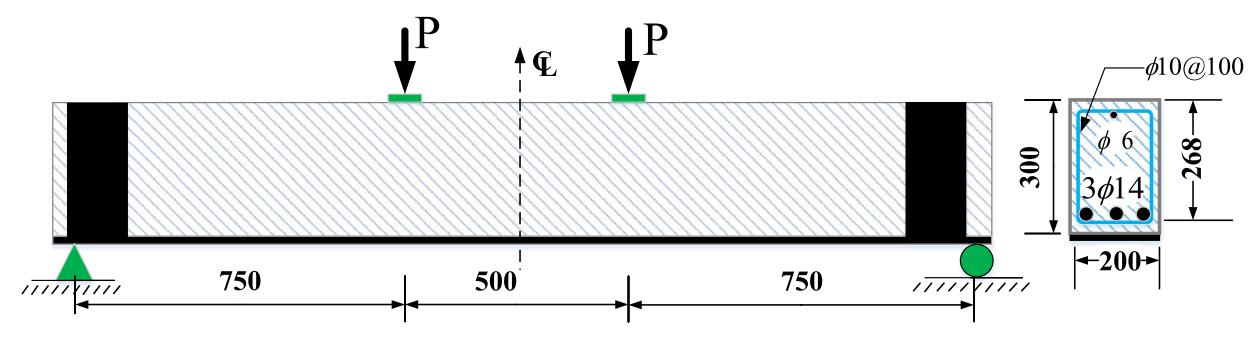

Figure 3. Beam specimen strengthened by CFRP and cross-section of beam (all dimensions arel in $\mathrm{mm}$ ) (Siddiqui, 2010). 


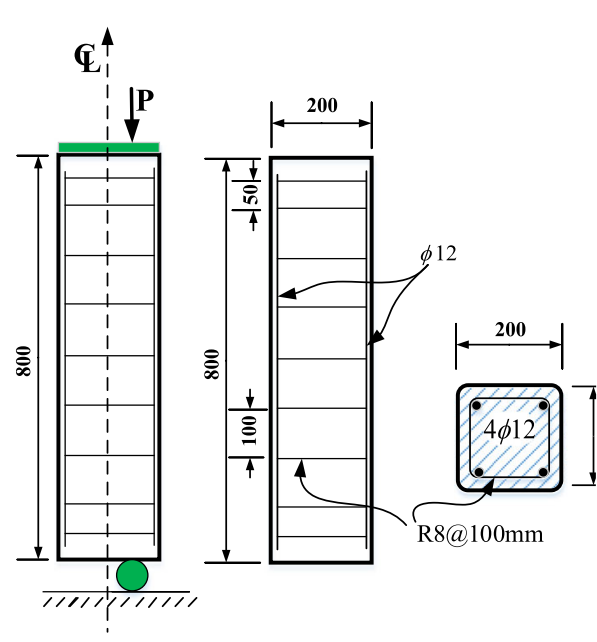

(a) Details of specimen reinforcement

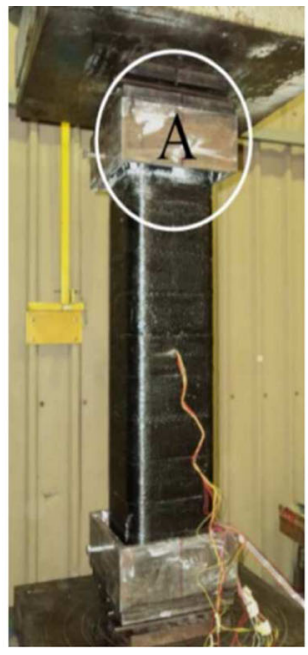

(b) FRP wrapping
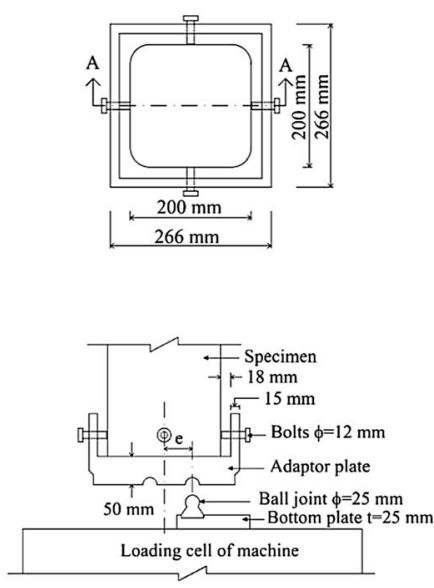

(c) Loading plate

Figure 4. Column specimen strengthened by CFRP (all dimensions are in $\mathrm{mm}$ ) (Hadi and Widiarsa, 2012).

Application of CFRP increased the ultimate failure load from $1950 \mathrm{kN}$ to $2076 \mathrm{kN}$ for NC and SC samples, respectively. This is about $6 \%$ enhancement in the ultimate strength of the column (Hadi and Widiarsa, 2012).

\subsection{Slab}

Six simply supported one-way spanning RC slabs were tested, four of which had an opening at the centre. All slabs were prismatic and rectangular in the cross-section and nominally $3400 \mathrm{~mm}$ long and of $160 \mathrm{~mm}$ depth, with a clear span of $3200 \mathrm{~mm}$. From this experiment, two slabs (with and without CFRP) were chosen. The width of the slab was $800 \mathrm{~mm}$, and the concrete cover was $20 \mathrm{~mm}$ on each side of the specimen. The 12-mm-diameter steel bars were used as longitudinal and transverse reinforcement, while the distance between bars was $200 \mathrm{~mm}$ and $400 \mathrm{~mm}$ in each direction, respectively, as seen in Figure 5. The control slab was loaded up to failure, and in the strengthened case, the CFRP was applied as the flexural strengthening scheme with two layers of CFRP (Figure 6). The concrete compressive strength was $47 \mathrm{MPa}$ and $49 \mathrm{MPa}$ for control and strengthened slab, respectively. The yield stress of reinforcement was $564 \mathrm{MPa}$.

The application of CFRP increased the ultimate failure load from $49.3 \mathrm{kN}$ to $80.8 \mathrm{kN}$ for NS and SS samples, respectively. This is about $64 \%$ enhancement in the ultimate strength of the slab (Smith and Kim, 2009).

\subsection{RC wall}

Eight one-way RC walls were tested with two different patterns. They had various opening sizes (5, 10, 20 and 30 percentage) and were located at the centre. For all the wall series, aspect ratios $(H / L)$, slenderness ratios $\left(H / t_{w}\right)$ and thinness ratios $\left(L / t_{w}\right)$ were 2, 20 and 10, respectively. From these experiments, two RC walls (with and without CFRP) were chosen. The height, width and thickness of the wall were $800 \mathrm{~mm}, 400 \mathrm{~mm}, 40 \mathrm{~mm}$, correspondingly. The concrete cover was $20 \mathrm{~mm}$ on each side of the specimen. The 5-mm-diameter steel bars were used as longitudinal and transverse reinforcement, and the reinforcement ratio of 0.004 and 0.007 in vertical and horizontal, respectively, as seen in Figures 7(a) and 8(a). The control wall was loaded up to failure in the strengthened cases; the CFRP was applied at the tension face as one layer of CFRP all around the corner and $45^{\circ}$ to the corner (Figures $7(\mathrm{~b}, \mathrm{c})$ and $8(\mathrm{~b}, \mathrm{c})$ ). The concrete compressive strength was $15.57 \mathrm{MPa}, 18.24 \mathrm{MPa}$ and 


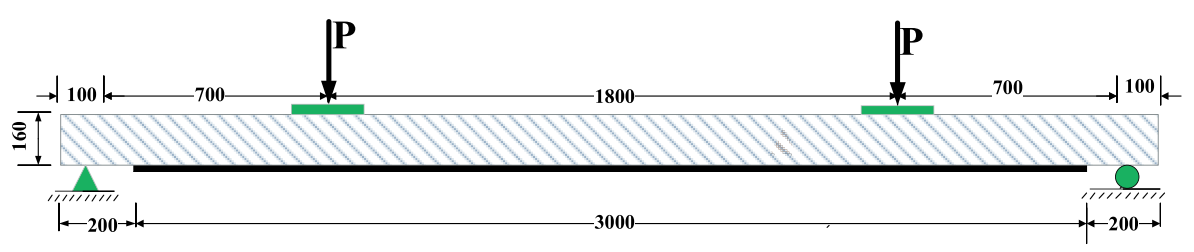

(a) Elevation view of slab

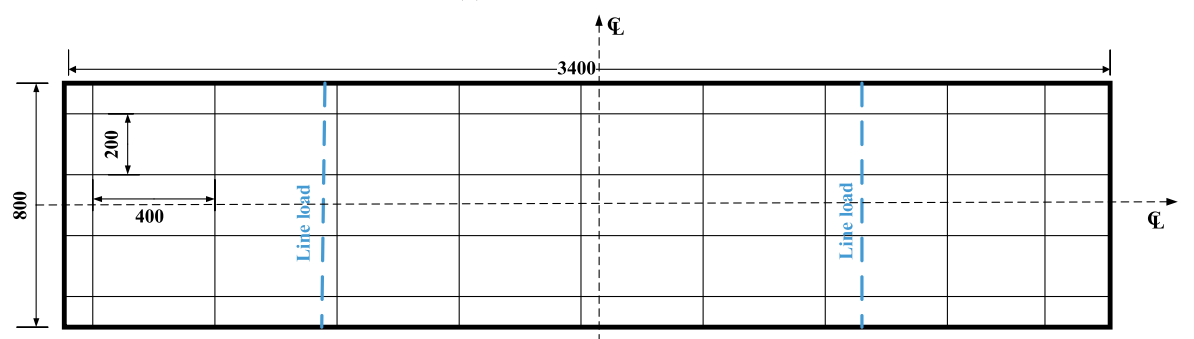

(b) Details of specimen reinforcement

Figure 5. Slab specimen (all dimensions are in mm) (Smith and Kim, 2009).

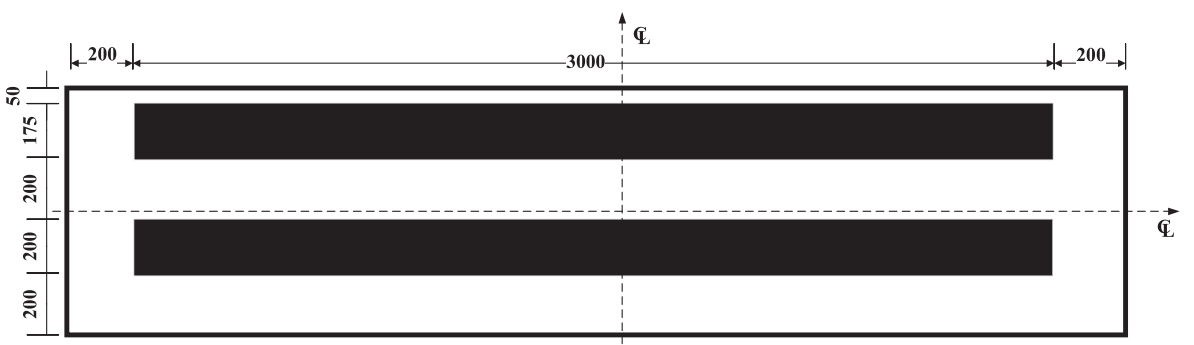

Figure 6. FRP application (all dimensions are in mm) (Smith and Kim, 2009).

16.36 MPa for NW1, SW1-A and SW1-D, respectively. This value for NW2, SW2-A and SW2-D was 15.79 MPa, 15.06 MPa and 17.04 MPa, correspondingly. The yield stress of reinforcement was 478 MPa.

The application of CFRP around the corner of the openings increased the ultimate failure load from $85 \mathrm{kN}$ to $108 \mathrm{kN}$ for NW1 and SW1-A specimens, respectively. This is about a $27 \%$ enhancement in the ultimate strength of RC wall. For SW1-D, the failure load was recorded as $138.5 \mathrm{kN}$, which is about a 62\% gain in the strength of the RC wall (Mohammed et al., 2013).

The application of CFRP around the corner of the openings increased the ultimate failure load from $73.7 \mathrm{kN}$ to $82 \mathrm{kN}$ for NW2 and SW2-A specimens, respectively. This is about an $11.2 \%$ enhancement in the ultimate strength of RC wall. For SW2-D, the failure load was recorded as $84.8 \mathrm{kN}$, which is about a 15\% gain in the strength of the RC wall (Mohammed et al., 2013).

\section{NUMERICAL SIMULATION (MATERIAL PROPERTIES AND CONSTITUTIVE MODELS)}

The materials used in the FEM analysis included steel reinforcing bars, concrete and FRP. In the following section, the input material properties and associated constitutive models are discussed.

\subsection{Modelling of steel reinforcing bars}

The stress-strain curve of the reinforcement bar is assumed to be elastic perfect plastic material and identical in compression and tension, as shown in Figure 9. In ABAQUS, the steel reinforcement is simulated as truss elements embedded in a concrete region in which the concrete and the reinforcement 


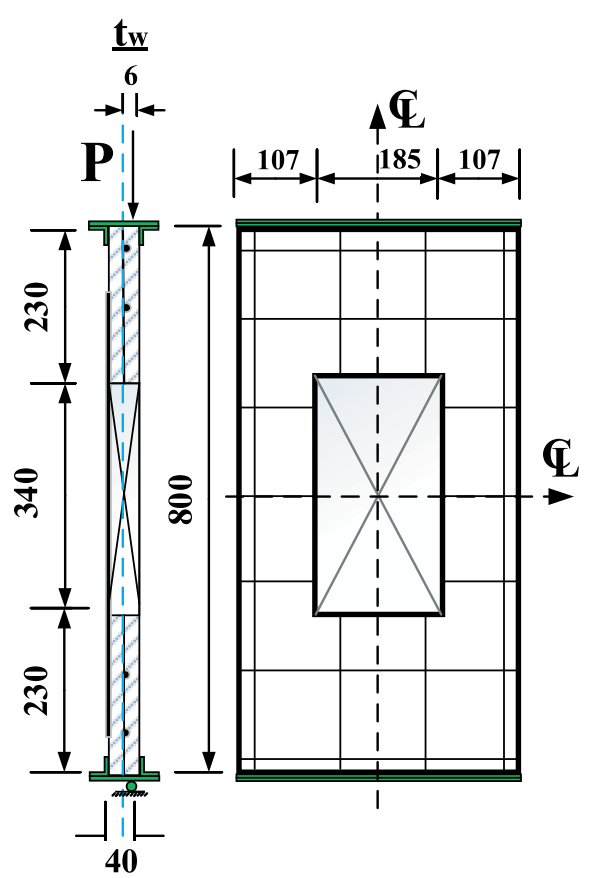

(a) NW1

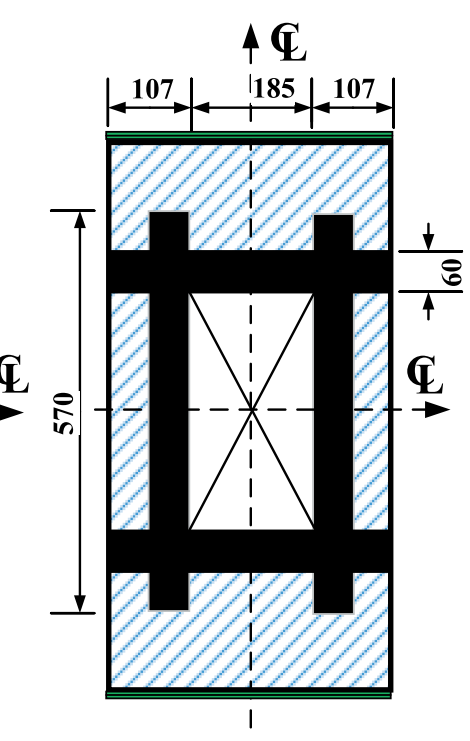

(b) SW1-A



(c) SW1-D

Figure 7. Details of specimen reinforcement and CFRP layout (all dimensions are in $\mathrm{mm}$ ) (Mohammed et al., 2013).

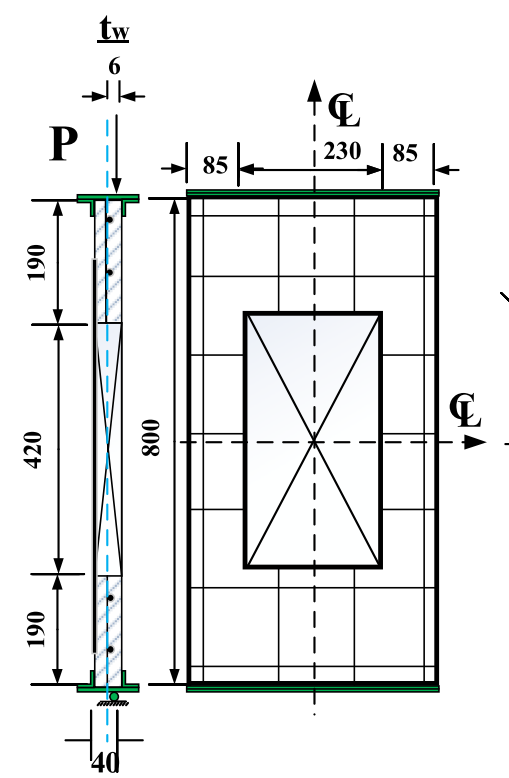

(a) NW2

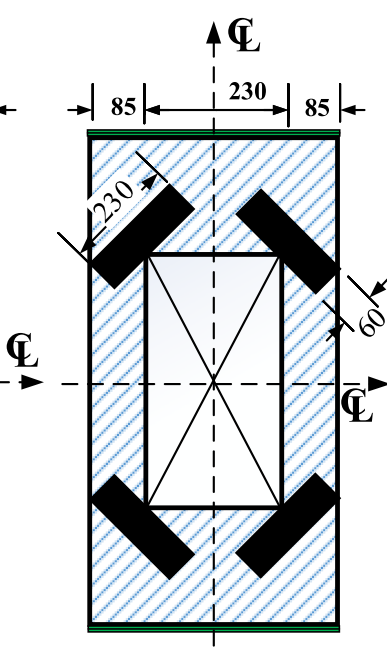

(b) SW2-A

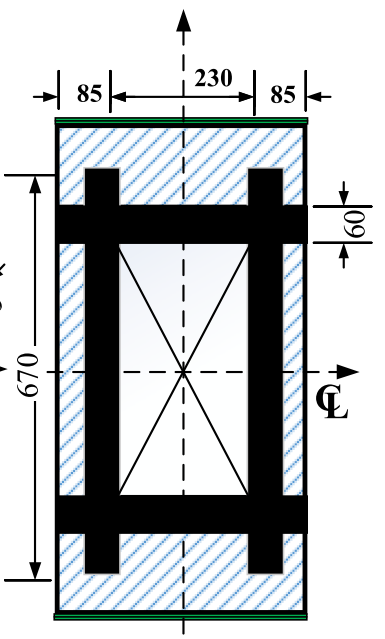

(c) SW2-D

Figure 8. Details of specimen reinforcement and CFRP layout (all dimensions are in mm) (Mohammed et al., 2013).

share the same node and perfect bond is assumed. The elastic modulus, $E_{s}$, and yield stress, $f_{y}$, for all experiments are presented in the previous section, and these values were used in the FEM model. For those experiments where elastic modulus was not reported, a value of $210 \mathrm{GPa}$ was considered in FEM simulation. A Poission's ratio of $v_{s}=0.3$ was used for reinforcement rebars in all models. 


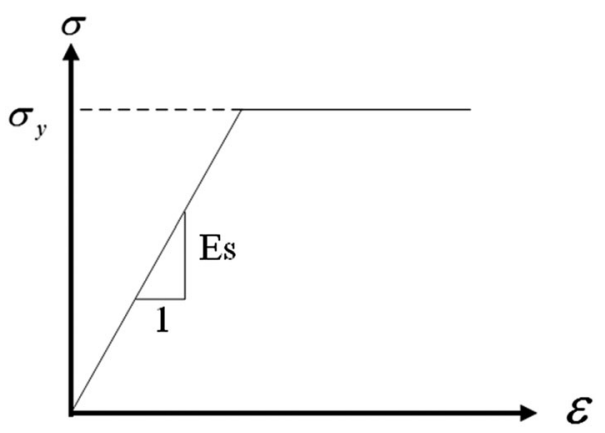

Figure 9. Schematic stress-strain behaviour of steel.

\subsection{Concrete}

The uniaxial compressive strength $f_{c}^{\prime}$ for all samples is presented in the previous section. The concrete strain $\varepsilon_{0}$, corresponding to the peak stress $f_{c}^{\prime}$, is usually around the range of 0.002-0.003. A representative value $\left(\varepsilon_{0}=0.003\right)$ suggested by ACI318-14 (2014) is used in the analysis. The Poission's ratio $v_{c}$ of concrete under uniaxial compressive strength ranges from 0.15 to 0.22 , and in this study, the Poission's ratio of concrete is assumed to be $v_{c}=0.2$ for all concrete instances. The initial modulus of elasticity of concrete $E_{c}$ is highly correlated to its compressive strength and can be calculated with reasonable accuracy from the empirical equation AS3600 (2009):

$$
\begin{gathered}
E_{c}=\rho^{1.5} \sqrt{f_{c}^{\prime}} \mathrm{MPa} \text { where } f_{c}^{\prime} \leq 40 \mathrm{MPa} \\
E_{c}=\rho^{1.5}\left[0.024 \sqrt{f_{c}^{\prime}}+0.12\right] \mathrm{MPa} \text { where } f_{c}^{\prime}>40 \mathrm{MPa}
\end{gathered}
$$

where $\rho$ is the concrete density. The stress-strain relationship proposed by (Saenz, 1964) was used to construct the uniaxial compressive stress-strain curve for normal strength concrete (for beam, slab).

$$
\sigma_{c}=\frac{E_{c} \varepsilon_{c}}{1+\left(R+R_{E}-2\right)\left(\frac{\varepsilon_{c}}{\varepsilon_{o}}\right)-(2 R-1)\left(\frac{\varepsilon_{c}}{\varepsilon_{o}}\right)^{2}+R\left(\frac{\varepsilon_{c}}{\varepsilon_{o}}\right)^{3}},
$$

where

$R=\frac{R_{E}\left(R_{\sigma}-1\right)}{\left(R_{\varepsilon}-1\right)^{2}}-\frac{1}{R_{\varepsilon}}, R_{E}=\frac{E_{c}}{E_{o}}, E_{o}=\frac{f_{c}^{\prime}}{\varepsilon_{o}}$ and $R_{\sigma}=4$ and $R_{\varepsilon}=4$ were used (Hu and Schnobrich, 1989).

For high-strength concrete, the stress-strain relationship proposed by (Hsu and Hsu, 1994) were used for $0 \leq \varepsilon \leq \varepsilon_{o}, n=1$; for $\varepsilon_{o} \leq \varepsilon \leq \varepsilon_{d}, n=1$ if $0<f_{c}^{\prime}<62 \mathrm{MPa} ; n=2$ if $62 \leq f_{c}^{\prime}<76 \mathrm{MPa}$, $n=3$ if $76 \leq f_{c}^{\prime}<90 \mathrm{MPa}$; and $n=5$ if $f_{c}^{\prime} \geq 90 \mathrm{MPa}$

$$
0 \leq \varepsilon \leq \varepsilon_{d}, \sigma_{c}=\frac{n f_{c}^{\prime} \beta\left(\varepsilon / \varepsilon_{o}\right)}{n \beta-1+\left(\varepsilon / \varepsilon_{o}\right)^{n \beta}} ; \beta=\left(\frac{f^{\prime} c}{65.23}\right)^{3}+2.59 .
$$

\subsection{Concrete in tension}

The tensile property of the reinforced concrete is modelled using a simple tension stiffening model. A linear softening model (Figure 10) is used to represent the post failure behaviour in tension where the area below the curve is the fracture energy $G_{f}$. In order to define the tension stiffening response, the stress-fracture energy approach is used with the fracture energy. For concrete under uniaxial tension, $f_{t}$ and $G_{f}$ may be estimated from the following equations (CEB-FIP, 1990): 


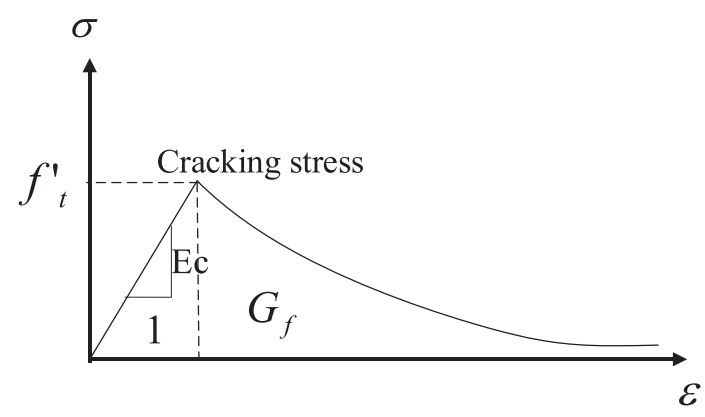

Figure 10. Schematic stress-strain behaviour of concrete in tension.

$$
\begin{gathered}
f_{t}=1.4\left(\frac{f_{c}^{\prime}-8}{10}\right)^{\frac{2}{3}} \\
G_{f}=\left(0.0469 d_{a}^{2}-0.5 d_{a}+26\right)\left(\frac{f_{c}^{\prime}}{10}\right)^{0.7},
\end{gathered}
$$

where $f_{t}$ the concrete tensile strength under is uniaxial tension, $G_{f}$ is the fracture energy required to create a stress-free crack over a unit area and $d_{a}$ is the maximum aggregate size. In the present study, if no test data are provided, it was assumed that $d_{a}=20 \mathrm{~mm}$. Note that in Equation (5), $f_{c}^{\prime}$ and $d_{a}$ are in MPa and $\mathrm{mm}$, respectively, and $G_{f}$ has a unit of $\mathrm{N} / \mathrm{mm}$ (Bažant and Becq-Giraudon, 2002).

\subsection{Concrete damage plasticity model}

The concept of either damage or plasticity, or both, can be applied to model the nonlinearity behaviour of concrete under compression (Maekawa, Okamura, and Pimanmas, 2003). Damage and plasticity are usually defined by the reduction of elastic constants and permanent deformation, respectively. In literature, both reduction in stiffness and unrecoverable deformation have been reported in concrete compression tests, indicating that the combination of the damage concept and plasticity is required to represent the nonlinear behaviour of concrete (Maekawa et al., 2003). In this study, the simulation of RC beams, columns, slabs and walls has been carried out using the concrete damage plasticity model. In order to represent the inelastic behaviour of concrete, the concrete damage plasticity in ABAQUS uses concepts of isotropic damage in combination with isotropic tensile and compressive plasticity (Hibbitt, Karlsson, and Sorensen, 2011). This method is briefly presented in this section. It assumes that the main two failure mechanisms are tensile cracking and compressive crushing of the concrete material. The key aspects of this model for concrete in compression are damage variable, yield criterion, the flow rule and viscous parameter. A summary of these factors are presented as follows.

\subsubsection{Damage}

It was assumed that the damage up to the concrete compressive strength $\left(\sigma_{u}\right)$ was zero, and after that point, the concrete compression damage increased monolithically in the softening branch (Jankowiak and Lodygowski, 2005). The compression damage was calculated according to Equation. (6):

$$
d_{t}=1-\frac{\sigma}{\sigma_{u}},
$$

where $\sigma$ is the axial stress of concrete on the descending branch and $\sigma_{u}$ is the stress of concrete at the peak point.

The concrete behaviour in tension was linear elastic until cracking was initiated. ABAQUS software has three options to simulate the behaviour of concrete in tension including: stress-strain, stress- 
displacement and fracture energy. To overcome unreasonable mesh sensitivity issues, the fracture energy approach was used instead of the tensile strain. This was calculated as a ratio of the total external energy supply $\left(G_{f}\right)$ per unit area required to initiate cracking in the concrete. This approach was suggested in a previous study (Sümer and Aktaş, 2014).

In order to minimize mesh sensitivity in the slab, the post-failure behaviour of concrete was specified in terms of the stress-displacement response (Enochsson et al., 2007). These damage parameters were similar to that of previous research carried out by Enochsson et al. (2007), where the fracture energy $\left(G_{f}\right)$ of the area under the stress-displacement curve was estimated to be $100 \mathrm{~N} / \mathrm{m}$.

It was assumed that the damage up to the concrete tensile strength $\left(f_{t}^{\prime}\right)$ was zero, and after that point, concrete tensile damage increased monolithically in the softening branch and was calculated based on the following formula:

$$
d_{t}=1-\frac{f_{i}^{\prime}}{f_{t}^{\prime}}
$$

where $f^{\prime}{ }_{i}$ is the axial stress of concrete on the descending branch and $f_{t}^{\prime}$ is the stress of concrete at the peak point.

\subsubsection{Yield criterion}

The concrete damage plasticity model makes use of the yield function of Lubliner et al. (1989), with the modifications proposed by Lee and Fenves (1998) to account for the different evolution of strength under tension and compression, as shown in Equation (8). The evolution of the yield surface is controlled by the hardening variables, $\widetilde{\varepsilon}_{t}^{p l}$ and $\widetilde{\varepsilon}_{c}^{p l}$ :

$$
F\left(\bar{\sigma}, \widetilde{\varepsilon}^{p l}\right)=\frac{1}{1-\alpha}\left(\bar{q}-3 \alpha \bar{p}+\beta\left(\widetilde{\varepsilon}^{p l}\right)\left\langle\widehat{\bar{\sigma}}_{\max }\right\rangle-\gamma\left\langle-\widehat{\bar{\sigma}}_{\max }\right\rangle\right)-\bar{\sigma}_{c}\left(\widetilde{\varepsilon}_{c}^{p l}\right) \leq 0,
$$

where

$$
\begin{gathered}
\alpha=\frac{\left(\sigma_{b o} / \sigma_{c o}\right)-1}{2\left(\sigma_{b o} / \sigma_{c o}\right)-1} ; 0.08 \leq \alpha \leq 0.12 \\
\beta=\frac{\bar{\sigma}_{c}\left(\widetilde{\varepsilon}_{c}^{p l}\right)}{\bar{\sigma}_{t}\left(\widetilde{\varepsilon}_{t}^{p l}\right)}(1-\alpha)-(1+\alpha) \\
\gamma=\frac{3\left(1-K_{c}\right)}{2 K_{c}-1},
\end{gathered}
$$

where $\widehat{\bar{\sigma}}_{\max }$ is the maximum principal effective stress and $\sigma_{b o} / \sigma_{c o}$ is the ratio of initial equibiaxial compressive yield stress to initial uniaxial compressive yield stress. The most reliable in this regard are the experimental results reported by Kupfer, Hilsdorf and Rusch (1969). After their approximation with the elliptic equation, uniform biaxial compression strength $\sigma_{b o}$ is equal to $1.16248 \sigma_{c o}$. The ABAQUS user's manual specifies default $\sigma_{b o} / \sigma_{c o}=1.16$, which was used in all simulation. $K_{c}$ is the strength ratio of concrete under equal biaxial compression to triaxial compression. Typical yield surfaces in the deviatoric plane are shown in Figure 11 for different values of $K$. It must satisfy the condition $0.5 \leq K_{c} \leq 1.0$. The default value (2/3) was used in all FEM simulation; $\bar{\sigma}_{c}\left(\widetilde{\varepsilon}_{c}{ }^{p l}\right)$ is the effective compressive cohesion stress and $\bar{\sigma}_{t}\left(\widetilde{\varepsilon}_{t}^{p l}\right)$ is the effective tensile cohesion stress.

The concrete damaged plasticity model assumes non-associated potential plastic flow. The flow potential $G$ used for this model is the Drucker-Prager hyperbolic function:

$$
G=\sqrt{\left(\xi \sigma_{t o} \tan \psi\right)^{2}+\bar{q}^{2}}-\bar{p} \tan \psi
$$

where $\sigma_{t o}$ is the uniaxial tensile stress at failure, $\psi$ is the dilation angle measured in the $p-q$ plane at 


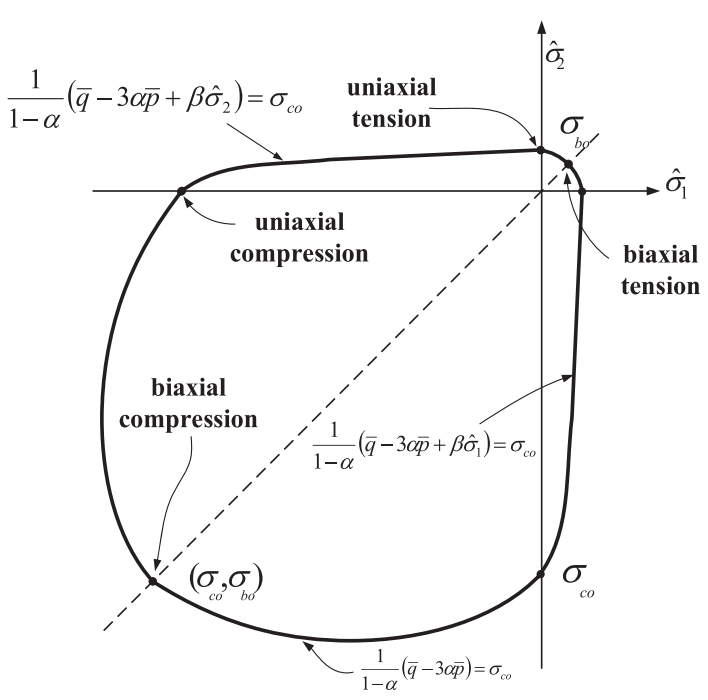

(a) in plane stress

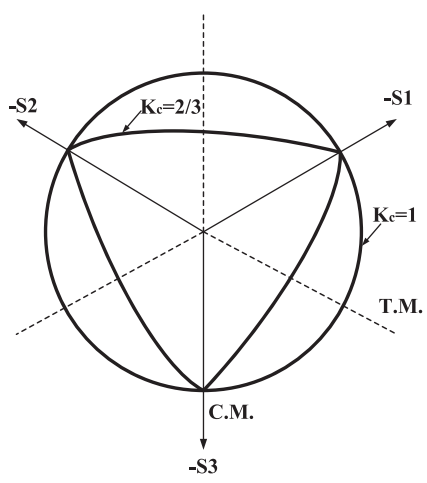

(b) in the deviatoric plane

Figure 11. Yield surfaces of the concrete damaged plasticity model in ABAQUS (Hibbitt et al., 2011).

high confining pressure and $\xi$ is a parameter, referred to as the eccentricity, that defines the rate at which the function approaches the asymptote (the flow potential tends to a straight line as the eccentricity tends to zero). The default flow potential eccentricity is $\xi=0.1$, which implies that the material has almost the same dilation angle over a wide range of confining pressure stress values. In all FEM analysis, $\xi=0.1$ was used. The dilation angle for concrete slab, beam, RC wall and column were $12^{\circ}, 37^{\circ}, 20^{\circ}$ and $8^{\circ}$, respectively. Similar dilation angles for each case study were used in previous FEM investigation (Enochsson et al., 2007; Majewski, Bobinski, and Tejchman, 2008; Obaidat et al., 2010).

\subsubsection{Viscous parameter}

The viscoplastic regularization can be applied using the concrete damage plasticity for the generalizing of the Devaut-Lions approach. A viscous parameter $\mu$ upgrades the plastic strain tensor, and the damage parameter is derived using additional relaxation time. The viscosity parameter was set to 0 as recommended by ABAQUS documentation; however, in specimens with a convergence problem, a small viscosity parameter $\left(\mu=10^{-5}\right)$ is considered after many sensitivity analyses were performed. This value is defined to improve the convergence rate in the concrete softening and stiffness degradation regimes. Similar approaches have been used in previous research studies where it is reported that if the viscosity parameter is 0 , the solution becomes plastic and divergence is obtained directly after cracking (Genikomsou and Polak, 2014).

\subsection{FRP properties}

The FRP material was considered as a linear elastic orthotropic material. Since the composite is unidirectional, it is obvious that the behaviour is essentially orthotropic. FRP primarily stressed in the fibre direction; therefore, the modulus in the fibre direction is the more important parameter. The elastic modulus in the fibre direction of the unidirectional FRP material used in the FEM was provided in the experiments. The FRP material properties are presented in Table. 4. A perfect bond was considered between FRP and concrete in all samples as the simulation of debonding is out of scope of this research.

The CFRP was simulated as an orthotropic material that exhibits a different modulus of elasticity in three main directions. This was achieved by using the 'Engineering Constant' option of the material definition section in ABAQUS software.

The modulus of elasticity in the main direction was considered as the value given in the experiments. The modulus of resin was designated as the modulus of elasticity in the other two directions 
Table 4. Fibre reinforced polymer material properties for all specimens.

\begin{tabular}{lcccc}
\hline Specimen & \multicolumn{3}{c}{ CFRP } \\
\cline { 2 - 5 } & $\begin{array}{c}\text { Nominal } \\
\text { thickness (mm) }\end{array}$ & $\begin{array}{c}\text { Modulus of } \\
\text { elasticity (MPa) }\end{array}$ & $\begin{array}{c}\text { Elongation at } \\
\text { rapture (mm/mm) }\end{array}$ & $\begin{array}{c}\text { Tensile strength } \\
(\mathrm{MPa})\end{array}$ \\
\hline Strengthened beam & 1.000 & 77280 & 0.0110 & 846 \\
Strengthened column & 0.450 & 75400 & 0.01860 & 1399 \\
Strengthened slab & 0.117 & 259000 & 0.0099 & 2559 \\
Strengthened wall & 0.167 & 230000 & 0.0210 & 4800 \\
\hline
\end{tabular}

( $E_{22}$ and $\left.E_{33}\right)$. In cases where the information of resin was not given in the experiments, 1-2\% of $E_{11}$ was assumed for $E_{22}$ and $E_{33}$ (Mosallam and Mosalam, 2003). Since the CFRP were subjected to uniaxial tension in the fibre direction only, these assumed parameters would not affect the uniaxial tensile behaviour of the CFRP.

The Poisson ratio was designated as $0.3,0.3$ and 0.45 for $v_{12}, v_{13}$ and $v_{23}$, respectively. The shear moduli $\left(G_{12}, G_{13}\right.$ and $\left.G_{23}\right)$ were calculated based on the following formula:

$$
G_{x y}=\frac{E_{x} E_{y}}{E_{x}+E_{y}+2 v_{x y} E_{x}} .
$$

\section{FEM ANALYSIS}

In all numerical models, a full scale of the element was analysed. In the FEM, eight-node brick elements (C3D8R) were used to model the concrete in beams, columns, slabs and RC walls. As the FRP are relatively thin in comparison with the concrete section, they were modelled by the four-node shell element. The FRP shell elements were attached to the concrete surface directly, and the interface between concrete and FRP was assumed to be fully bonded. Mesh convergence sensitivity has been carried out for all specimens in order to have a little difference in the element behaviour and failure load. An attempt was carried out to have a square element for all specimens. An appropriate contact was also considered between loading plate and concrete element.

\subsection{Mesh sensitivity}

Mesh convergence sensitivity was performed for all specimens in order to achieve little difference in the element behaviour and failure load. An attempt was carried out to have a square element for all specimens. Herein, the mesh sensitivity study for RC slab was presented. Three mesh configurations were used (Figure 12) including coarse, medium and fine mesh. In order to investigate the mesh sensitivity in the RC slab, the sizes of mesh for other parts, such as reinforcement bars, were maintained. Using a coarse mesh resulted in lower peak loads compared with the experimental outcomes. The deflection response was much lower than that of the medium and fine mesh. The peak loads predicted for the varied mesh densities were provided in Table. 5. The difference between the ultimate failure loads by using fine and medium mesh was approximately identical, while the time cost for the fine mesh was much higher. Therefore, the medium size mesh was adopted.

\subsection{Riks method}

In this study, the Riks method has been used for analysis of all numerical models. The Riks method is usually used to predict the unstable, geometrically nonlinear collapse of a structure and can include the nonlinear materials. Additionally, the Riks method often follows an eigenvalue buckling analysis to provide complete information about a structure's collapse. As finding the failure load of the structure was the main purpose of this study and in order to have a consistent analysis method in all RC elements, the Riks method was preferred. Automatic stability was also used to avoid a divergence solution. For considering the geometric nonlinearity, Nlgeom setting was also activated. 


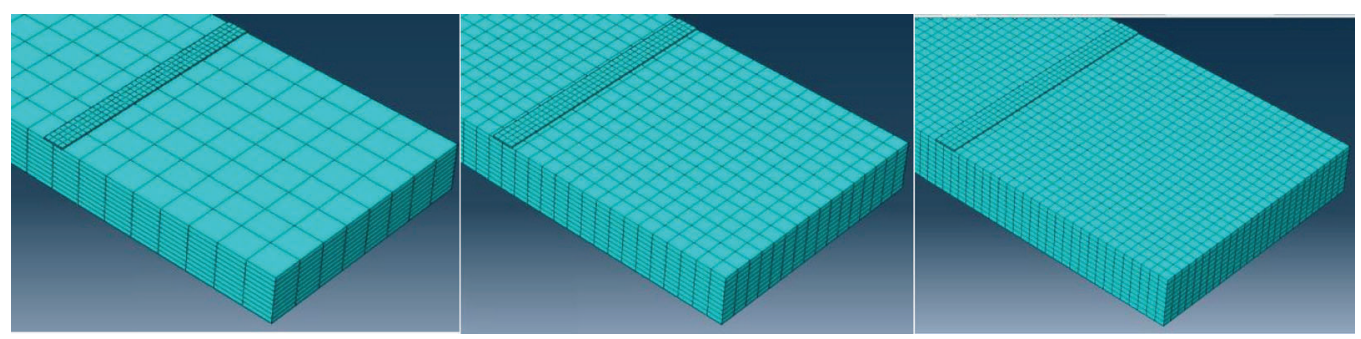

(a) Coarse

(b) Medium

(c) Fine

Figure 12. Mesh sensitivity study for RC slab.

Table 5. Mesh configurations used during the convergence study of RC slab.

\begin{tabular}{lcccc}
\hline Mesh & The size of the mesh seed & Number of elements & $P_{\max }$ & $P_{\max } / P_{\text {exp }}$ \\
\hline Coarse & 100 & 3562 & 41.6 & 0.84 \\
Medium & 50 & 11722 & 55.5 & 1.12 \\
Fine & 30 & 31620 & 57.3 & 1.16 \\
\hline
\end{tabular}

\section{RESULTS AND DISCUSSION}

\subsection{Crack pattern}

Figures 13-18 show a comparison between the plastic strain distributions obtained from finite element analysis as well as the crack patterns obtained from the experiments for the control and strengthened specimens. In ABAQUS, by visualizing maximum principle plastic strain (PE), which in the material model is defined as cracking strain, it is possible to determine the area experiencing cracks or fractures. The cracks obtained in the experiments and correlated maximum PE in the simulations are similar, which indicates that models are able to capture the failure mechanism in the specimens.

Figure 13(a) shows the failure of RC beam reported by Siddiqui (2010) where the failure mode was concrete crushing. The applied CFRP anchor in both sides of the beam tackled the debonding issue in the sample. The FEM results also present a similar pattern at the mid-span of the beam (Figure 13(b)).

Figure 14 shows the failure of the concrete column with eccentric axial load where the concrete column experienced a severe damage in the compression side. An analogous pattern has been detected in the FEM.

Figure 15(a) shows the cracks in the bottom side of RC slab under line load, and several distributed cracks (parallel to the line load direction) were reported in the experiment. An analogous pattern has been detected in the FEM, which is shown as discontinuous lines in Figure 15(b). Both numerical and experimental results show that cracks were distributed between two restraints, and the section out of this area did not experience any crack.

Figures 16-19 show the cracks of RC wall in both experiments and numerical simulation. Based on the experimental observation reported by Mohamamd et al. (2010, 2013), RC walls usually experience cracks in the upper corner of the opening with a similar pattern being obtained in the FEM. A comparison of crack pattern between the FEM results of NW and SW is presented in Figures 17 and 18. The crack patterns of all RC walls were horizontal, with failure occurring near the top corner of the opening.

\subsection{Ultimate strength}

In order to show how the FRP changes the ultimate strength of RC members, a comparison between the ultimate failure load of samples before and after strengthening has been presented in Tables. 6 and 8 . These results indicate that the application of FRP considerably enhances the ultimate strength of columns, beams and slabs. However, there are negligible changes in the RC wall strengthened by CFRP. 


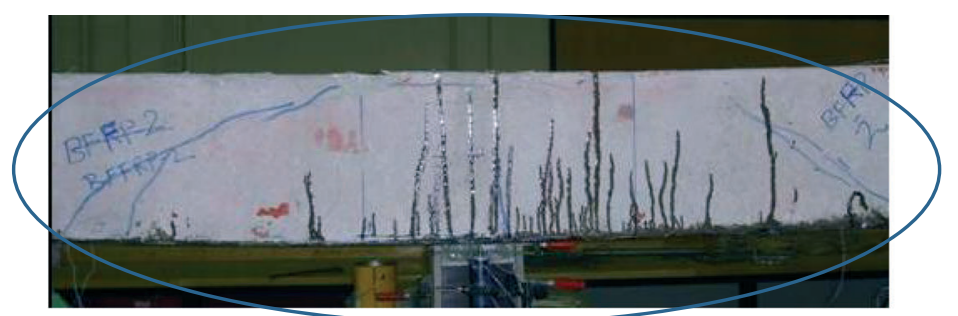

(a) Experiment (Siddiqui, 2010)



(b) FEM maximum PE

Figure 13. Crack pattern of experiment and correlated maximum PE in FEM for SB.

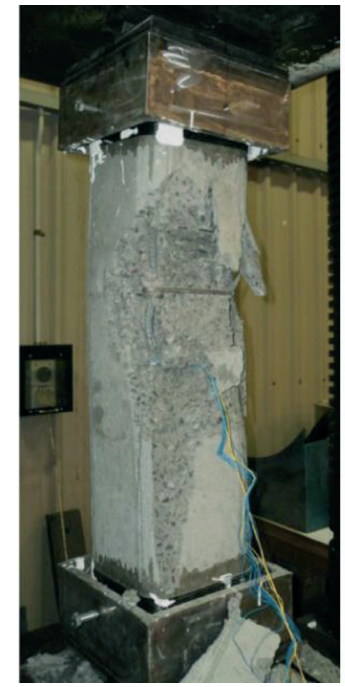

(a) Experiment (Hadi and Widiarsa, 2012)

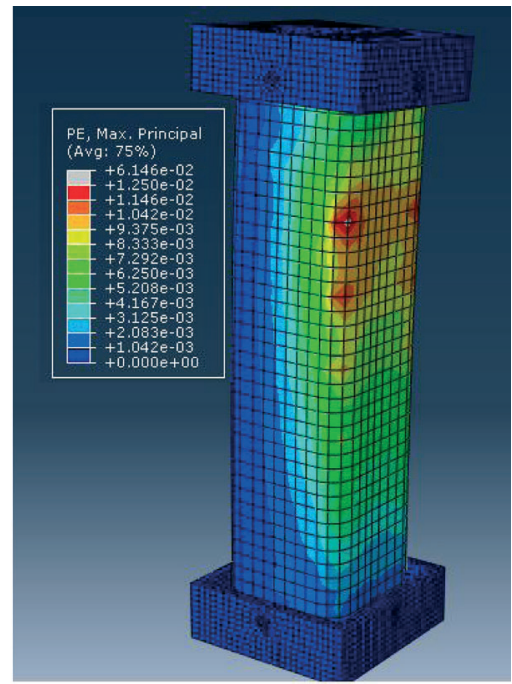

(b) FEM maximum PE

Figure 14. Crack pattern of experiment and correlated maximum PE in FEM for NC.

In beams and slabs, the orientation of FRP is perpendicular to the loading direction; therefore, it makes a significant contribution to FRP in a load-carrying capacity. In fact, when the FRP is applied in the axial direction of beams, it has the highest stiffness and strength in its fibre direction. In columns, the concrete is completely confined to FRP, and in this case, the FRP experienced a pressure perpendicular to the FRP orientation. However, in RC strengthened walls, the loading application is parallel to the FRP orientation and the wall experiences shortening in a vertical direction. In this condition, FRP may not considerably contribute to enhancing the ultimate strength. 


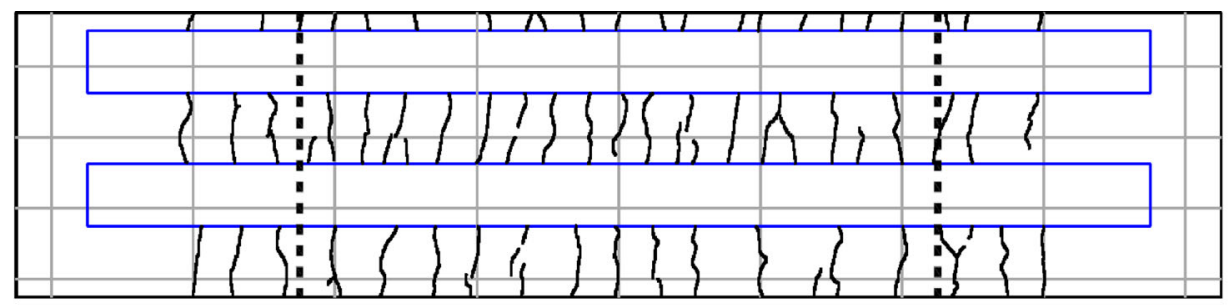

(a) Experiment (Smith and Kim, 2009)

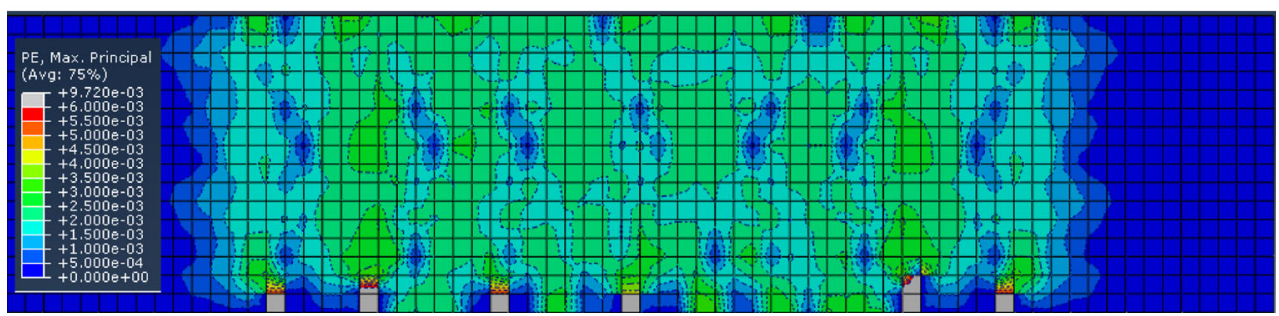

(b) FEM

Figure 15. Crack pattern of experiment and correlated maximum PE in FEM for SS in the bottom side.

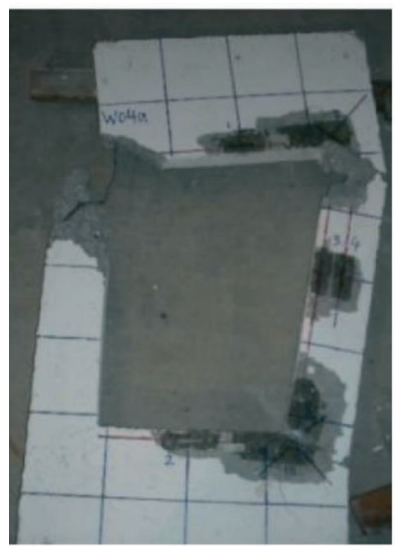

(a) NW2

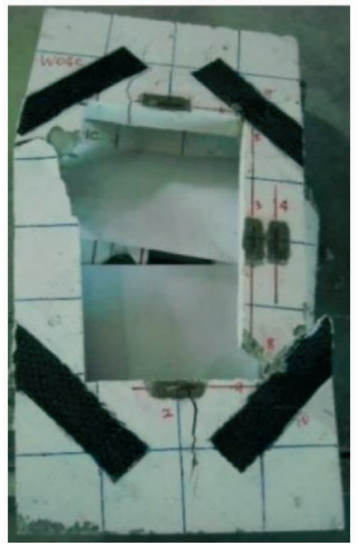

(b) SW2-D

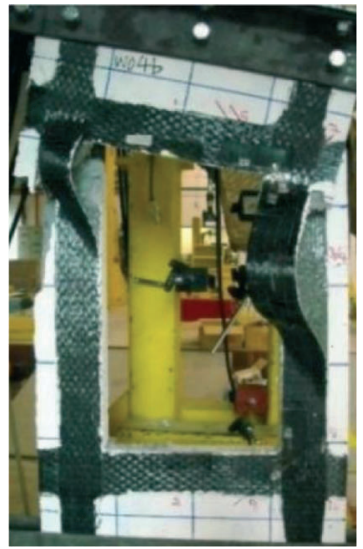

(c) SW2-A

Figure 16. Crack pattern of RC walls (Mohammed et al., 2013).

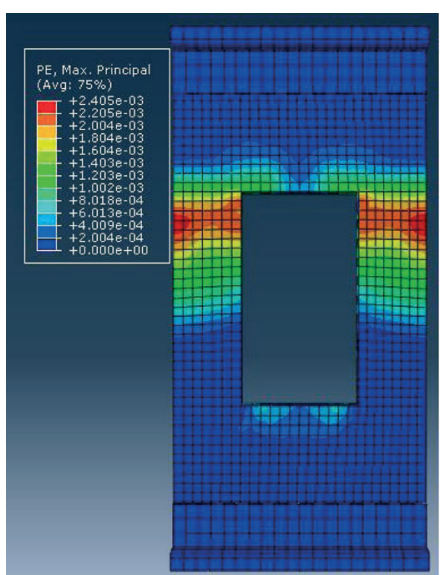

(a) NW1

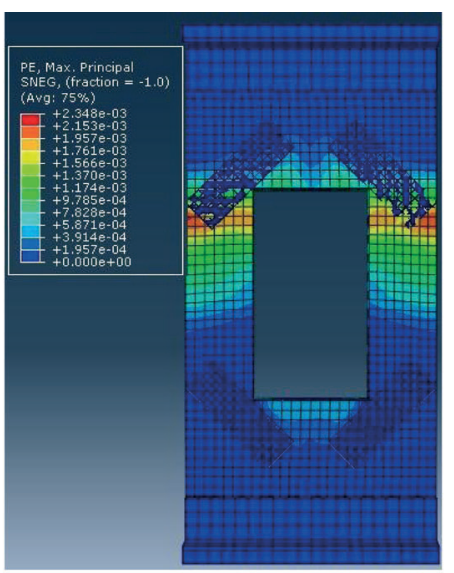

(b) SW1-D

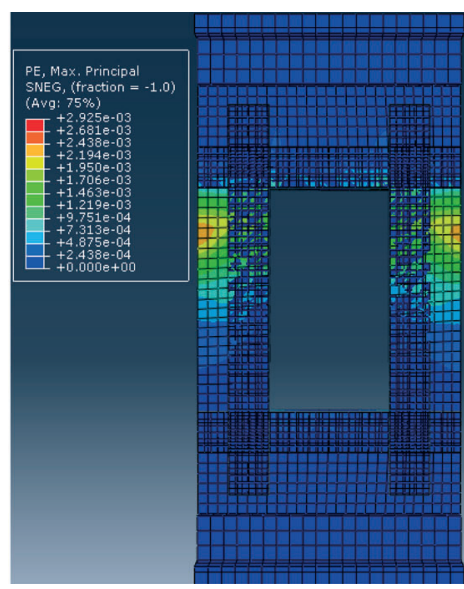

(c) SW1-A

Figure 17. FEM maximum PE of RC walls (concrete strength=15.57 MPa). 


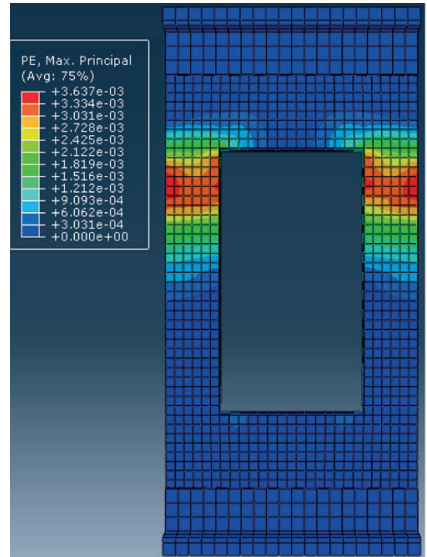

(a) NW2

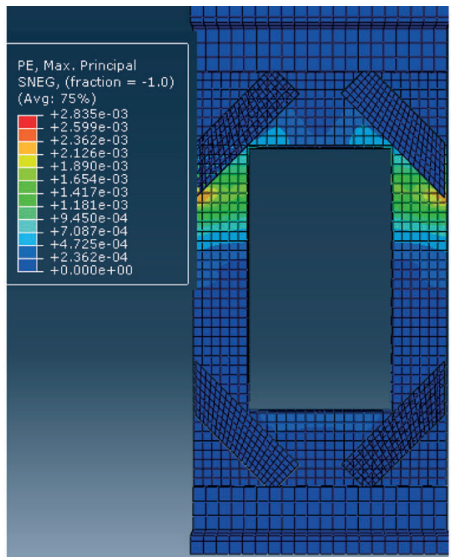

(b) SW2-D

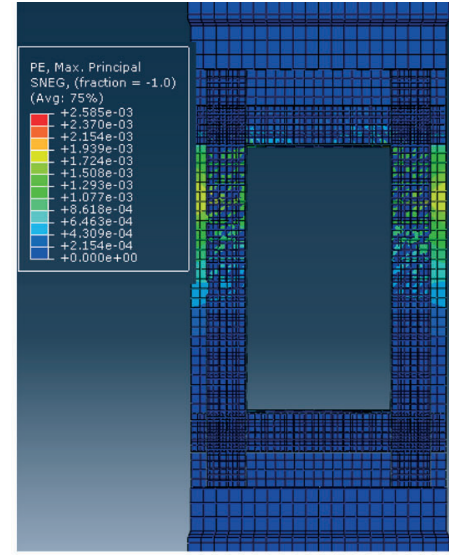

(c) SW2-A

Figure 18. FEM maximum PE of RC walls (concrete strength $=15.57 \mathrm{MPa}$ ).

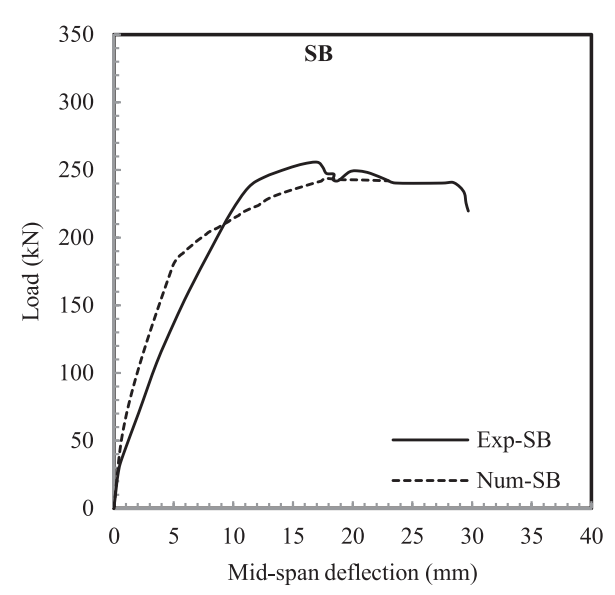

Beam (SB)

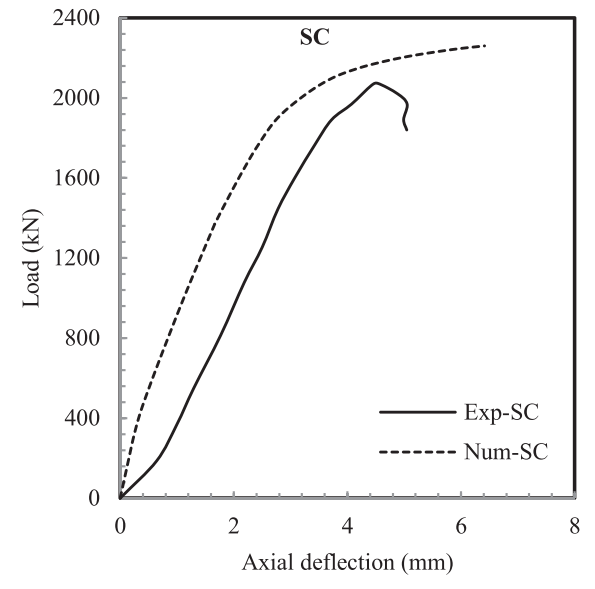

Column(SC)

Figure 19. Comparison between load-deflection relationships of experiments and FEM.

Table 6. Results of ultimate load for beam, column and slab

\begin{tabular}{lccccc}
\hline \multirow{2}{*}{ Structural Element } & $\begin{array}{c}\text { Model } \\
\text { designation }\end{array}$ & \multicolumn{2}{c}{ Ultimate load $(\mathrm{kN})$} & & Numerical \\
\cline { 3 - 4 } & & Experimental & Numerical & & Experimental \\
\hline Beam (Siddiqui, 2010) & NB & 197.20 & 193.00 & 0.98 \\
Column (Hadi and Widiarsa, 2012) & SB & & 255.20 & 243.00 & 0.95 \\
& NC & & 1950.00 & 2007.00 & \\
Slab (Smith and Kim, 2009) & SC & & 2076.00 & 2264.00 & \\
& NS & & 49.30 & 55.52 & \\
& SS & 80.80 & 87.95 & \\
\hline
\end{tabular}

An enhancement of about $29.5 \%$ was reported in the ultimate strength of the RC beam in Siddiqui, (2010). The simulation results show a $26 \%$ enhancement in the ultimate failure load for SB. The CFRP application in slabs improved the ultimate strength gain of the slab by about $64 \%$, while an increase of about 58\% was observed in the FEM. The ultimate strength of the SC was increased by about $6.5 \%$ and $12.8 \%$ in experiments and FEM simulation, respectively. A comparison between the experiments and FEM for beams, columns and slabs is presented in Table. 6. 
The load-deflection graphs for one sample of the beam, column and slab were presented in Figures 19 and 20 and compared with the experiment outcomes were well matched. However, the load-deflection graph for RC wall was not provided in the experiments; therefore, only the outcome of the FEM was presented.

In RC walls, the results of FEM for NW are compared with the experiment, and a considerable discrepancy (up to 48\%) was observed. Therefore, an attempt has been performed to compare both experimental and FEM simulation results with existing empirical formula. Many researchers have studied the structural behaviour and failure load of RC walls with openings (Saheb and Desayi, 1989, 1990; Doh and Fragomeni, 2005; Doh and Fragomeni, 2006; Fragomeni et al., 2012) and have proposed a simplified formula to calculate the ultimate failure load. Based on the material properties and dimensions of the NW specimen $f_{c}^{\prime}<25 \mathrm{MPa}$, slenderness ratio $\left(H / t_{w}<16\right)$, aspect ratio $(H / L<2)$, thinness ratio $\left(L / t_{w}<8\right)$ and opening aspect ratio $\left(H_{o} / L_{o} \approx 1.8\right)$, using the formula suggested by (Saheb and Desayi, 1989, 1990) is preferred. The detailed information about the experiments and formula can be found in the original paper. Their proposed formula for ultimate load in RC walls with openings in one-way action is as follows:

$$
P_{u o}=\left(k_{1}-k_{2} \cdot \chi\right) \cdot P_{u},
$$

where $k_{1}=1.25$ and $k_{1}=1.22$ for walls in one-way action,

where $\chi=\frac{A o}{A}+\frac{\eta}{L}, A_{o}=L_{o} t, A=L t, \eta=\left[\left(\frac{L}{2}\right)-\bar{\eta}\right], \bar{\eta}=\frac{\left(\frac{L^{2} t}{2}-L_{o} t \eta_{o}\right)}{\left(L t-L_{o} t\right)}$ and $L_{o}$ and $H_{o}$ are the dimensions of the opening in $\mathrm{mm}, \eta$ is the distance between the centres of gravity of an RC wall section in plane with and without openings in $\mathrm{mm}$, and $\eta_{o}$ and $\bar{\eta}$ are distances of the centres of gravity of the opening and of a wall without an opening from the left edge of the wall, respectively, in $\mathrm{mm}$.

Also, $p_{u}$ can be calculated as follows, for wall panels in one-way action and for

$$
\begin{gathered}
\frac{H}{L}<2 . P_{u}=0.55 \varphi\left[A_{g} f^{\prime}{ }_{c}+\left(f_{y}-f^{\prime}{ }_{c}\right) A_{s v}\right]\left[1-\left(\frac{H}{32 t_{w}}\right)^{2}\right]\left[1.2-\left(\frac{H}{10 L}\right)\right], \\
\frac{H}{L} \geq 2 . P_{u}=0.55 \varphi\left[A_{g} f^{\prime}{ }_{c}+\left(f_{y}-f^{\prime}{ }_{c}\right) A_{s v}\right]\left[1-\left(\frac{H}{32 t_{w}}\right)^{2}\right],
\end{gathered}
$$

where $\varphi$ is the capacity reduction factor, $A_{g}$ is the gross cross-sectional area of RC walls in plane in $\mathrm{mm}^{2}$ and $f_{y}$ and $f^{\prime}{ }_{c}$ are the yield strength of steel and concrete in MPa, respectively. $A_{s v}$ is the area

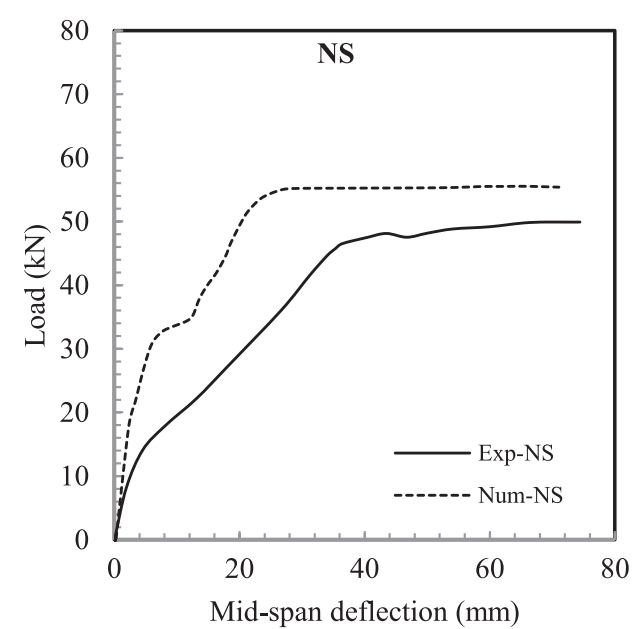

Slab (NS)

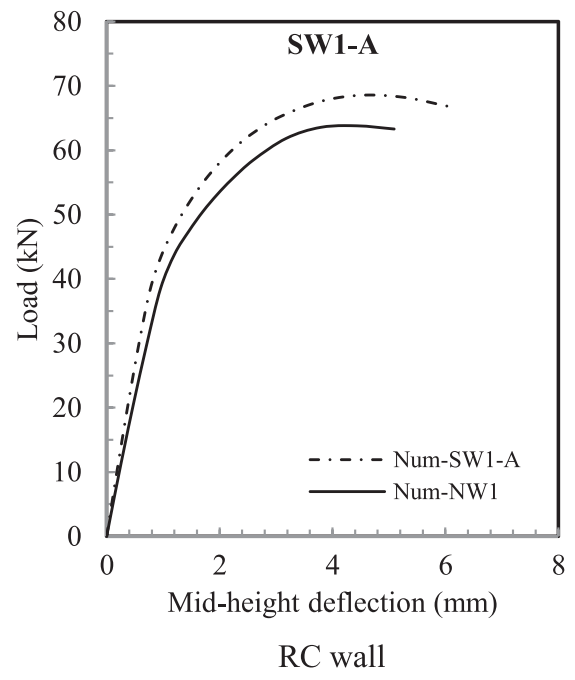

$\mathrm{RC}$ wall

Figure 20. Comparison between load-deflection relationships of experiments and FEM. 
of vertical steel in the $\mathrm{RC}$ wall in $\mathrm{mm}^{2} ; H$ is the height of the wall in $\mathrm{mm} ; t_{w}$ is the thickness of the wall in $\mathrm{mm}$, and $L$ is the length of the wall in $\mathrm{mm}$. A detailed comparison of ultimate failure load for NW1 and NW2 are presented in Table. 7. The result shows about a $6.3 \%$ and $6.9 \%$ difference between the numerical and empirical formula for NW1 and NW2, respectively, and also represents that the FEM was capable to capture the RC wall behaviour and ultimate failure load.

For SW1-A (with a concrete strength of 18.27 MPa) the application of CFRP enhanced the ultimate load of the wall by about $27 \%$ in the experimental test, while an increase of $13.5 \%$ was observed in the FEM. In order to consider the pure contribution of CFRP in the ultimate load, another simulation was conducted on walls with and without CFRP with the same concrete strength $(15.57 \mathrm{MPa})$. It was noted that the CFRP contributed towards the enhancement of the ultimate strength of the wall by only $6 \%$. For SW1-D (with concrete strength of $16.36 \mathrm{MPa}$ ), the application of CFRP enhanced the ultimate load of the wall by about $63 \%$ in the experimental test, while an increase of $3 \%$ was observed in the FEM. In order to consider the pure contribution of CFRP in the ultimate load, another simulation was conducted on the wall with and without CFRP with the same concrete strength (15.57 MPa), and it is noted that the CFRP contributed towards the enhancement of the ultimate strength of the wall by only $0.3 \%$.

The same procedure has been conducted to find out the effect of CFRP confinement on SW2-A and SW2-D. The results showed that CFRP only increased the capacity of RC wall $6.3 \%$ and $4.9 \%$ for SW2-A and SW2-D, respectively. However, these values have been reported as $11.2 \%$ and $15 \%$ in experiments (Mohammed et al., 2013). In FEM, it is evident that the CFRP has greater contribution in ultimate strength of the wall when the opening size increases. These results contradict the outcome of experiments where, with an increase in the opening size, less CFRP contribution on the wall capacity has been reported. A comparison between the outcomes of experiments and numerical analysis for NW, SW-A and SW-D is presented in Table. 8.

The outcome from the FEM analysis contradicts the results obtained by (Mohammed et al., 2013). By applying CFRP in $45^{\circ}$ to the opening corners, the ultimate strength of the wall was enhanced significantly $(62 \%$ and $15 \%)$, while a negligible $(0.3 \%$ and $4.9 \%)$ change was observed in the FEM. Additionally, unlike the experiment's outcome, the FEM simulation shows that the pattern applied to the SW-A had a better effect on the strength of the RC wall, as the weakest part of the wall was strengthened. Further, unlike the experiment's results, FEM outcomes show that by increasing the opening size, a greater contribution of CFRP is achieved.

Based on the outcomes from experiments and numerical studies, there is evidence that CFRP has a great influence on the ultimate strength of beams, columns and slabs. However, in the case of the RC wall, there is a significant discrepancy between the FEM and experiment outcomes. This may arise from the CFRP's fibre orientation that is parallel to the loading direction and walls experiencing a

Table 7. Results of ultimate load for RC walls with opening and without CFRP

\begin{tabular}{lcccccc}
\hline \multirow{2}{*}{$\begin{array}{l}\text { Model } \\
\text { designation }\end{array}$} & \multicolumn{3}{c}{ Ultimate load $(\mathrm{kN})$} & & Eq. (16) & Eq. (16) \\
\cline { 2 - 3 } \cline { 7 - 7 } & Experimental & Numerical & Eq. (16) & & Experimental & Numerical \\
\hline NW1 & 85.00 & 63.80 & 60.00 & & 0.71 & 0.94 \\
NW2 & 73.00 & 49.00 & 52.40 & & 0.72 & 1.07 \\
\hline
\end{tabular}

Table 8. Results of ultimate load for RC walls with and without CFRP layout

\begin{tabular}{lccccc}
\hline \multirow{2}{*}{$\begin{array}{l}\text { Model } \\
\text { designation }\end{array}$} & \multicolumn{3}{c}{ Ultimate load $(\mathrm{kN})$} & & Numerical \\
\cline { 2 - 4 } & Experimental & \multicolumn{3}{c}{ Numerical for $f_{c}^{\prime}:$} & Experimental \\
\cline { 2 - 5 } & & $18.2 \mathrm{MPa}$ & $15.6 \mathrm{MPa}$ & $16.4 \mathrm{MPa}$ & \\
\hline NW-1 & 85.00 & - & 63.80 & - & 0.75 \\
SW1-A & 108.00 & 72.45 & 67.60 & - & 0.63 \\
SW1-D & 138.50 & - & 64.00 & 65.70 & 0.46 \\
NW-2 & 73.70 & - & 49.00 & - & 0.66 \\
SW2-A & 82.00 & - & 52.10 & - & 0.64 \\
SW2-D & 84.80 & - & 51.40 & - & 0.61 \\
\hline
\end{tabular}


shortening in the fibre's direction. As a result of scarce experiments and theoretical studies on the strengthening of RC walls using CFRP, this field needs urgent attention to support a better understanding of the behaviour of the wall and CFRP's contribution to the ultimate strength. Further investigations are also required to determine the behaviour of $\mathrm{RC}$ walls with various material properties and CFRP patterns under different boundary conditions (two, three and four sides restrained).

\section{CONCLUSIONS}

This paper presents a finite element analysis that has been validated against laboratory tests of two RC beams, two columns, two slabs and six walls. It is evident that the FRP orientation has a critical effect in ultimate failure load of FRP-strengthened RC members. The CFRP sheet orientation in a strengthened beam, column and slab is perpendicular to the loading direction, and it contributed to the carrying of the load by stretching through its principal direction. However, in the RC wall panels, the loading direction and CFRP's fibre orientation are parallel. As RC walls experience a shortening in the fibre's direction, a lower contribution of CFRP in ultimate failure load was observed. Based on the FEM simulation and the existing experiments, a distinct difference between the ultimate strength in strengthened RC walls has been realized. The FEM was capable of simulating the behaviour of the RC members and the FRP contribution in the ultimate strength of beams, columns and slabs. However, for RC walls, consistency in the results of both experiments and numerical simulations was not achieved. Therefore, further numerical, theoretical and experimental analyses are required to be able to study the behaviour of the strengthened RC wall. Additionally, the effect of the boundary condition (concrete walls with three and four side restraints) as well as the opening size and location should be considered to be able to properly evaluate the contribution of the FRP in search of the ultimate strength of the strengthened RC wall. Unquestionably, it is essential that different FRP pattern applications also be delved into to ensure a full understanding of the optimum strengthening solutions for practical applications. To conclude, the provision of a simplified guideline/formula for calculating the capacity of strengthened walls is a necessary requirement for engineering application. A comprehensive experimental and numerical study is currently underway at Griffith University to propose reliable recommendations for engineering application. The study will test a number of concrete walls with different parameters, such as various boundary conditions and CFRP layout.

\section{REFERENCES}

Abdelrahman K, El-Hacha R. 2012. Behavior of large-scale concrete columns wrapped with CFRP and SFRP sheets. Journal of Composites for Construction 16(4): 430-9.

ACI 440, 2002. Guide for the design and construction of externally bonded FRP systems for strengthening concrete structures, American Concrete Institute.

Alagusundaramoorthy P, Harik I, Choo C. 2003. Flexural behavior of R/C beams strengthened with carbon fiber reinforced polymer sheets or fabric. Journal of Composites for Construction 7(4): 292-301.

Almusallam TH, Al-Salloum YA. 2001. Ultimate strength prediction for RC beams externally strengthened by composite materials. Composites Part B: Engineering 32(7): 609-19.

Alsayed SH, Al-Salloum YA, Almusallam TH. 2000. Fibre-reinforced polymer repair materials-some facts. Proceedings of the ICE-Civil Engineering 138(3): 131-134.

Altin S, Anil O, Toptas T, Kara ME. 2011. Retrofitting of shear damaged RC beams using CFRP strips. Steel and Composite Structures 11(3): 207-23.

Anil Ö, Kaya N, Arslan O. 2013. Strengthening of one way RC slab with opening using CFRP strips. Construction and Building Materials 48: 883-93.

AS3600. 2009, Concrete structures, standards australia, Sydney, Australia.

Bakis C, Bank LC, Brown V, Cosenza E, Davalos J, Lesko J, Machida A, Rizkalla S, Triantafillou T. 2002. Fiber-reinforced polymer composites for construction-state-of-the-art review. Journal of Composites for Construction 6(2): 73-87.

Barghi M, Azadbakht M, Hadad M. 2012. Evaluating the ductility and shear behaviour of carbon fibre reinforced polymer and glass fibre reinforced polymer reinforced concrete columns. The Structural Design of Tall and Special Buildings 21(4): 249-64.

Bažant ZP, Becq-Giraudon E. 2002. Statistical prediction of fracture parameters of concrete and implications for choice of testing standard. Cement and Concrete Research 32(4): 529-56.

Bisby L, Ranger M. 2010. Axial-flexural interaction in circular FRP-confined reinforced concrete columns. Construction and Building Materials 24(9): 1672-81. 
Cao S, Chen J, Teng J, Hao Z, Chen J. 2005. Debonding in RC beams shear strengthened with complete FRP wraps. Journal of Composites for Construction 9(5): 417-28.

CEB-FIP. 1990, Model code, FIB-Féd. Int. du Béton.

Ceroni F. 2010. Experimental performances of RC beams strengthened with FRP materials. Construction and Building Materials 24(9): 1547-59.

Chin SC, Shafiq N, Nuruddin MF. 2014. FRP as strengthening material for reinforced concrete beams with openings—a review. KSCE Journal of Civil Engineering 19(1): 213-9.

Clarke JL. 2003. Strengthening concrete structures with fibre composites. Proceedings of the ICE—Structures and Buildings [Online], 156. Available: http://www.icevirtuallibrary.com/content/article/10.1680/stbu.2003.156.1.49.

Doh J-H, Fragomeni S. 2005. Evaluation of experimental work on concrete walls in one and two-way action. Australian Journal of Structural Engineering 6(1): 37.

Doh J-H, Fragomeni S. 2006. Ultimate load formula for reinforced concrete wall panels with openings. Advances in Structural Engineering 9(1): 103-15.

El-Saikaly G, Chaallal O. 2015. Fatigue behavior of RC T-beams strengthened in shear with EB CFRP L-shaped laminates. Composites: Part B 68: 100-12.

El Maaddawy T, Soudki K. 2008. Strengthening of reinforced concrete slabs with mechanically-anchored unbonded FRP system. Construction and Building Materials 22(4): 444-55.

Elgabbas F, El-Ghandour AA, Abdelrahman AA, El-Dieb AS. 2010. Different CFRP strengthening techniques for prestressed hollow core concrete slabs: experimental study and analytical investigation. Composite Structures 92(2): 401-11.

Enochsson O, Lundqvist J, Täljsten B, Rusinowski P, Olofsson T. 2007. CFRP strengthened openings in two-way concrete slabs —an experimental and numerical study. Construction and Building Materials 21(4): 810-26.

FIB14 .2001. Externally bonded FRP reinforcement for RC structures, Bulletin 14, FIB-Féd.Int. du Béton.

Fragomeni S, Doh J-H, Lee D. 2012. Behavior of axially loaded concrete wall panels with openings: an experimental study. Advances in Structural Engineering 15(8): 1345-58.

Gajdosova K, Bilcik J. 2013. Full-scale testing of CFRP-strengthened slender reinforced concrete columns. Journal of Composites for Construction 17(2): 239-48.

Genikomsou A, Polak M. Finite element analysis of a reinforced concrete slab-column connection using ABAQUS. Structures Congress 2014, 2014. ASCE, 813-c23.

Grace NF, Sayed G, Soliman A, Saleh K. 1999. Strengthening reinforced concrete beams using fiber reinforced polymer (FRP) laminates. ACI Structural Journal 96(5): 865-875.

Hadi M. 2006. Behaviour of FRP wrapped normal strength concrete columns under eccentric loading. Composite Structures 72 (4): 503-11.

Hadi MN. 2006. Comparative study of eccentrically loaded FRP wrapped columns. Composite Structures 74: 127-135.

Hadi MN. 2007. Behaviour of FRP strengthened concrete columns under eccentric compression loading. Composite Structures 77(1): 92-6.

Hadi MN, Widiarsa IBR. 2012. Axial and flexural performance of square RC columns wrapped with CFRP under eccentric loading. Journal of Composites for Construction 16(6): 640-9.

Hibbitt H, Karlsson B, Sorensen P. 2011. ABAQUS analysis users manual version 6.10. Dassault Systèmes Simulia Corp.: Providence, RI, USA.

Hollaway LC, Head PR. 2001. Chapter 5-FRP strengthening and repair of reinforced concrete systems. Advanced Polymer Composites and Polymers in the Civil Infrastructure, Head LCHR, ed.. Elsevier Science Ltd: Oxford.

Hong W-K, Park S-C, Kim H-C, Kim J-M, Kim S-I, Lee S-G. 2010. Experimental study of reinforced concrete beams strengthened with a GFRP channel and CFRP sheets. Structural Design of Tall and Special Buildings 19(5): 497-517.

Hosny A, Shaheen H, Abdelrahman A, Elafandy T. 2006. Performance of reinforced concrete beams strengthened by hybrid FRP laminates. Cement and Concrete Composites 28(10): 906-13.

Hsu L, Hsu C-T. 1994. Complete stress-strain behaviour of high-strength concrete under compression. Magazine of Concrete Research 46(169): 301-12.

Hu H-T, Schnobrich WC. 1989. Constitutive modeling of concrete by using nonassociated plasticity. Journal of Materials in Civil Engineering 1(4): 199-216.

Ibrahim AM, Mahmood MS. 2009. Finite element modeling of reinforced concrete beams strengthened with FRP laminates. European Journal of Scientific Research 30(4): 526-41.

ISIS .2001. Retrofitting concrete structures with fiber reinforced polymers, Canada.

Jankowiak T, Lodygowski T. 2005. Identification of parameters of concrete damage plasticity constitutive model. Foundations of Civil and Environmental Engineering 6(1): 53-69.

JSCE .2000. Recommendations for upgrading of concrete structures with use of continuous fiber sheets: Research Committee on Upgrading of Concrete Structures with Use of Continuous Fiber Sheets, Japanese Society of Civil Engineers.

Jumaat M, Alam A. 2008. Experimental and analytical investigations on the structural behaviour of steel plate and CFRP laminate flexurally strengthened reinforced concrete beams. Journal of Applied Sciences 8(23): 4383-9.

Khalifa A, Nanni A. 2000. Improving shear capacity of existing RC T-section beams using CFRP composites. Cement and Concrete Composites 22(3): 165-74.

Khalifa A, Nanni A. 2002. Rehabilitation of rectangular simply supported RC beams with shear deficiencies using CFRP composites. Construction and Building Materials 16(3): 135-46.

Kim H, Lee KH, Lee YH, Lee J. 2012. Axial behavior of concrete-filled carbon fiber-reinforced polymer composite columns. Structural Design of Tall and Special Buildings 21(3): 178-93. 
Kim N, Kim YH, Kim HS. 2015. Experimental and analytical investigations for behaviors of RC beams strengthened with tapered CFRPs. Structural Engineering and Mechanics 53(6): 1067-81.

Kotynia R, Abdel Baky H, Neale KW, Ebead UA. 2008. Flexural strengthening of RC beams with externally bonded CFRP systems: test results and 3D nonlinear FE analysis. Journal of Composites for Construction 12(2): 190-201.

Kupfer H, Hilsdorf HK, Rusch H. 1969. Behavior of concrete under biaxial stresses. ACI Journal proceedings 66(8): 656-66.

Lee J, Fenves GL. 1998. Plastic-damage model for cyclic loading of concrete structures. Journal of Engineering Mechanics 124(8): 892-900.

Li J, Hadi M. 2003. Behaviour of externally confined high-strength concrete columns under eccentric loading. Composite Structures 62(2): 145-53.

Limam O, Foret G, Ehrlacher A. 2003. RC two-way slabs strengthened with CFRP strips: experimental study and a limit analysis approach. Composite Structures 60(4): 467-71.

Lu W-Y, Yu H-W, Chen C-L, Liu S-L, Chen T-C. 2015. High-strength concrete deep beams with web openings strengthened by carbon fiber reinforced plastics. Computers and Concrete 15(1): 21-35.

Lubliner J, Oliver J, Oller S, Onate E. 1989. A plastic-damage model for concrete. International Journal of Solids and Structures 25(3): 299-326.

Maaddawy TE. 2009. Strengthening of eccentrically loaded reinforced concrete columns with fiber-reinforced polymer wrapping system: experimental investigation and analytical modeling. Journal of Composites for Construction 13(1): 13-24.

Maekawa K, Okamura H, Pimanmas A. 2003. Non-linear Mechanics of Reinforced Concrete. Taylor \& Francis Group: UK.

Majewski T, Bobinski J, Tejchman J. 2008. FE analysis of failure behaviour of reinforced concrete columns under eccentric compression. Engineering Structures 30: 300-317.

Matthys S, Toutanji H, Taerwe L. 2006. Stress-strain behavior of large-scale circular columns confined with FRP composites. Journal of Structural Engineering 132(1): 123-33.

Meneghetti LC, Garcez MR, da Silva Filho LCP, Gastal FPSL, Bittencourt TN. 2014. Fatigue life of RC beams strengthened with FRP systems. Structural Concrete 15(2): 219-28.

Mohammed BS, Ean L, Hossain KMA. 2010. CFRP composites for strengthening of reinforced concrete walls with openings. International Journal of Engineering Research and Applications 1: 1841-1852.

Mohammed BS, Ean L, Malek M. 2013. One way RC wall panels with openings strengthened with CFRP. Construction and Building Materials 40: 575-83.

Mosallam AS, Mosalam KM. 2003. Strengthening of two-way concrete slabs with FRP composite laminates. Construction and Building Materials 17(1): 43-54.

Nanni A. 2003. North American design guidelines for concrete reinforcement and strengthening using FRP: principles, applications and unresolved issues. Construction and Building Materials 17(6): 439-46.

Napoli A, Bank LC, Brown VL, Martinelli E, Matta F, Realfonzo R. 2013. Analysis and design of RC structures strengthened with mechanically fastened FRP laminates: a review. Composites: Part B 55: 386-99.

Neale K. 2000. FRPs for structural rehabilitation: a survey of recent progress. Progress in Structural Engineering and Materials 2(2): 133-8.

Norris T, Saadatmanesh H, Ehsani MR. 1997. Shear and flexural strengthening of R/C beams with carbon fiber sheets. Journal of Structural Engineering 123(7): 903-11.

Obaidat YT, Heyden S, Dahlblom O. 2010. The effect of CFRP and CFRP/concrete interface models when modelling retrofitted RC beams with FEM. Composite Structures 92(6): 1391-8.

Pantelides CP, Gergely J, Reaveley LD, Volnyy VA. 1999. Retrofit of RC bridge pier with CFRP advanced composites. Journal of Structural Engineering 125(10): 1094-9.

Parvin A, Wang W. 2001. Behavior of FRP jacketed concrete columns under eccentric loading. Journal of Composites for Construction 5(3): 146-52.

Pendhari SS, Kant T, Desai YM. 2008. Application of polymer composites in civil construction: a general review. Composite Structures 84(2): 114-24.

Pham TM, Doan LV, Hadi MN. 2013. Strengthening square reinforced concrete columns by circularisation and FRP confinement. Construction and Building Materials 49: 490-9.

Rahai AR, Saberi MR. 2011. Experimental and numerical investigation of damaged concrete beams strengthened with FRP composed of different fibres and resins. Structural Design of Tall and Special Buildings 20(8): 972-85.

Rahimi H, Hutchinson A. 2001. Concrete beams strengthened with externally bonded FRP plates. Journal of Composites for Construction 5(1): 44-56.

Sadeghian P, Rahai A, Ehsani M. 2010. Experimental study of rectangular RC columns strengthened with CFRP composites under eccentric loading. Journal of Composites for Construction 14(4): 443-50.

Saenz LP. 1964. Discussion of equation for the stress-strain curve of concrete by Desayi and Krishnan. ACI Journal 61(9): 1229-35.

Saheb SM, Desayi P. 1989. Ultimate strength of RC wall panels in one-way in-plane action. Journal of Structural Engineering 115(10): 2617-30.

Saheb SM, Desayi P. 1990. Ultimate strength of RC wall panels with openings. Journal of Structural Engineering 116(6): $1565-77$.

Seliem H, Seracino R, Sumner E, Smith S. 2011. Case study on the restoration of flexural capacity of continuous one-way RC slabs with cutouts. Journal of Composites for Construction 15(6): 992-8. 
Sen T, Jagannatha Reddy HN. 2013. Strengthening of RC beams in flexure using natural jute fibre textile reinforced composite system and its comparative study with CFRP and GFRP strengthening systems. International Journal of Sustainable Development Building and Environment 2(1): 41-55.

Siddiqui NA. 2010. Experimental investigation of RC beams strengthened with externally bonded FRP composites. Latin American Journal Solids and Structures. 6(4): 343-62.

Smith ST, Kim SJ. 2009. Strengthening of one-way spanning RC slabs with cutouts using FRP composites. Construction and Building Materials 23(4): 1578-90.

Smith ST, Teng J. 2002. FRP-strengthened RC beams. I: review of debonding strength models. Engineering Structures 24(4): 385-95.

Song X, Gu X, Li Y, Chen T, Zhang W. 2013. Mechanical behavior of FRP-strengthened concrete columns subjected to concentric and eccentric compression loading. Journal of Composites for Construction 17(3): 336-46.

Spadea G, Bencardino F, Swamy R. 1998. Structural behavior of composite RC beams with externally bonded CFRP. Journal of Composites for Construction 2(3): 132-7.

Sümer Y, Aktaş M. 2014. Finite Element Modeling of Existing Cracks on Pre-loaded Reinforced Concrete Beams. Arabian Journal for Science and Engineering 39(4): 2611-2619.

Tan K, Zhao H. 2004. Strengthening of openings in One-Way reinforced-concrete slabs using carbon fiber-reinforced polymer systems. Journal of Composites for Construction 8(5): 393-402.

Tanarslan HM, Kumanlioglu A, Sakar G. 2015. An anticipated shear design method for reinforced concrete beams strengthened with anchoraged carbon fiber-reinforced polymer by using neural network. Structural Design of Tall and Special Buildings 24(1): 19-39.

Teng J, Chen J, Smith ST, Lam L. 2003. Behaviour and strength of FRP-strengthened RC structures: a state-of-the-art review. Proceedings of the ICE-Structures and Buildings 156(1): 51-62.

Teng JG, Chen J-F, Smith ST, Lam L. 2002. FRP: strengthened RC structures. John Wiley \& Sons: UK

Thanoon WA, Jaafar MS, Razali A, Kadir MR, Noorzaei J. 2005. Repair and structural performance of initially cracked reinforced concrete slabs. Construction and Building Materials 19(8): 595-603.

Toutanji H, Han M, Gilbert J, Matthys S. 2010. Behavior of large-scale rectangular columns confined with FRP composites. Journal of Composites for Construction 14(1): 62-71.

TR 55. 2012. Design Guidance for Strengthening Concrete Structures Using Fibre Composite Materials. Concrete Society: UK.

Tumialan G, Nanni A, Ibell T, Fukuyama H. 2002. FRP composites for strengthening civil infrastructure around the world. SAMPE Journal 38(5): 9-15.

Wu Y-F, Jiang C. 2013. Effect of load eccentricity on the stress-strain relationship of FRP-confined concrete columns. Composite Structures 98: 228-241.

zgür Yurdakul Ö, Avşar Ö. 2015. Structural repairing of damaged reinforced concrete beam-column assemblies with CFRPs. Structural Engineering and Mechanics 54(3): 521-43.

Zhang Z, Hsu C-TT. 2005. Shear strengthening of reinforced concrete beams using carbon-fiber-reinforced polymer laminates. Journal of Composites for Construction 9(2): 158-69.

Zhang Z, Hsu C-T T, Moren J. 2004. Shear strengthening of reinforced concrete deep beams using carbon fiber reinforced polymer laminates. Journal of Composites for Construction 8(5): 403-14.

Zhao X-L, Zhang L. 2007. State-of-the-art review on FRP strengthened steel structures. Engineering Structures 29(8): $1808-23$

\section{AUTHORS’ BIOGRAPHIES}

Mehdi Mohmamdpour Lima is a PhD candidate in the School of Engineering at Griffith University, Gold Coast Campus, Australia. He obtained Bachelor Degree in Civil Engineering from Tabriz University and Master Degree in Earthquake Engineering from Iran University of Science and Technology. His $\mathrm{PhD}$ topic is numerical and experimental study on the behaviour of externally bonded CFRP-strengthened reinforced concrete walls with opening.

Jeung-Hwan Doh is a Senior Lecturer in the School of Engineering at Griffith University, Gold Coast Campus, Australia. He obtained Bachelor of Honours and Master of Honours in his Civil Engineering Degree from the University of Wollongong and obtained $\mathrm{PhD}$ from Griffith University. His current research focus is on reinforced concrete walls, slabs, construction material embodied energy consumption and sustainable design method for concrete structures.

Muhammad Hadi is an Assoc. Professor of Structural Engineering at the University of Wollongong, Australia. He obtained his PhD from The University of Leeds, UK. Dr Hadi is a Fellow of the Australian Institution of Engineers and a Fellow of the American Society of Civil Engineers. He published more than 200 research papers in the areas of concrete structures, concrete-steel and FRP composite 
structures. He supervised $11 \mathrm{PhDs}$ and $7 \mathrm{ME}$ (Hons) to date and is currently advising $20 \mathrm{PhD}$ candidates.

Dane Miller is a Research Assistant at the School of Engineering at Griffith University, Gold Coast Campus, Australia. He obtained the first class Honours in his Bachelor degrees for both Civil Engineering and Environmental Science from Griffith University and obtained his PhD from Griffith University. His research focuses on environmentally efficient and sustainable design methodology for concrete buildings. 